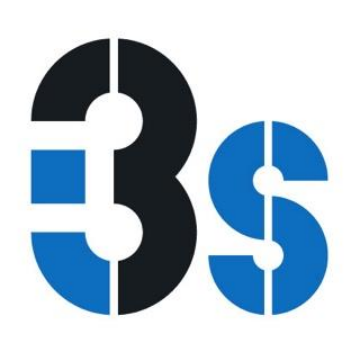

\title{
Glycomic analysis of gastric carcinoma cells discloses glycans as modulators of RON receptor tyrosine kinase activation in cancer
}

\author{
Stefan Mereiter 1, 2, 3; Ana Magalhães 1, 2; Barbara \\ Adamczyk 4; Chunsheng Jin 4; Andreia Almeida 5, 6; \\ Lylia Drici 7; Maria Ibáñez-Vea 7; Catarina Gomes 1,2; \\ José A. Ferreira 1, 2, 8; Luis P. Afonso 9; Lúcio L. Santos \\ 8, 10; Martin R. Larsen 7; Daniel Kolarich 5; Niclas G. \\ Karlsson 4; Celso A. Reis 1, 2, 3, 11, \#
}

1. I3S - Instituto de Investigação e Inovação em Saúde, University of Porto, Portugal; 2. Institute of Molecular Pathology and Immunology of the University of Porto - IPATIMUP, Porto, Portugal; 3. Institute of Biomedical Sciences of Abel Salazar - ICBAS, University of Porto, Portugal; 4. Department of Medical Biochemistry and Cell Biology, Institute of Biomedicine, Sahlgrenska Academy, University of Gothenburg, Sweden; 5. Department of Biomolecular Systems, Max Planck Institute of Colloids and Interfaces, 14424 Potsdam, Germany; 6. Free University Berlin, Berlin, Germany 7. Department of Biochemistry and Molecular Biology, University of Southern Denmark, Odense, Denmark; 8. Experimental Pathology and Therapeutics Group, Portuguese Institute of Oncology of Porto, Portugal, 9. Department of Pathology, Portuguese Institute of Oncology of Porto, Portugal, 10. Department of Surgical Oncology, Portuguese Institute of Oncology of Porto, Portugal 11. Medical Faculty, University of Porto, Portugal

\#To whom correspondence should be addressed: Celso A. Reis

Originally published in Biochim Biophys Acta. 2016 Aug;186o(8):1795-808. doi: 10.1016/j.bbagen.2015.12.016. Epub 2015 Dec 22.

Abbreviations: SLe ${ }^{a}$, Sialyl Lewis A; SLe ${ }^{\mathrm{X}}$, Sialyl Lewis X; PTM, Post-translational modifications; RTK, Receptor tyrosine kinase; IHC, Immunohistochemistry; PLA, Proximity ligation assay; GC, gastric cancer; HILIC-FLD-UPLC, hydrophilic interaction liquid chromatography fluorescence detection ultra-performance liquid chromatography; 
Keywords: ST3GAL4, Sialyl Lewis X (SLeX), RON, gastric cancer, glycome, sialome

\begin{abstract}
Background: Terminal $\alpha 2-3$ and $\alpha 2-6$ sialylation of glycans precludes further chain elongation, leading to the biosynthesis of cancer relevant epitopes such as sialyl-Lewis $X\left(S e^{X}\right)$. SLe ${ }^{X}$ overexpression is associated with tumor aggressive phenotype and patients' poor prognosis.

Methods: MKN45 gastric carcinoma cells transfected with the sialyltransferase ST3GAL4 were established as a model overexpressing sialylated terminal glycans. We have evaluated at the structural level the glycome and the sialoproteome of this gastric cancer cell line applying liquid chromatography and mass spectrometry. We further validated an identified target expression by proximity ligation assay in gastric tumors.

Results: Our results showed that $\mathrm{ST}_{3} \mathrm{GAL}_{4}$ overexpression leads to several glycosylation alterations, including reduced $\mathrm{O}$-glycan extension and decreased bisected and increased branched $\mathrm{N}$-glycans. A shift from a2-6 towards a2-3 linked sialylated N-glycans was also observed. Sialoproteomic analysis further identified 47 proteins with significantly increased sialylated $\mathrm{N}$-glycans. These included Integrins, Insulin receptor, Carcinoembryonic antigens and RON receptor tyrosine kinase, which are proteins known to be key players in malignancy. Further analysis of RON confirmed its modification with SLe ${ }^{x}$ and the concomitant activation. SLe ${ }^{x}$ and RON co-expression was validated in gastric tumors.

Conclusion: The overexpression of $\mathrm{ST}_{3} \mathrm{GAL}_{4}$ interferes with the overall glycophenotype of cancer cells affecting a multitude of key proteins involved in malignancy. Aberrant glycosylation of the RON receptor was shown as an alternative mechanism of oncogenic activation.

General significance: This study provides novel targets and points to an integrative tumor glycomic/proteomic-profiling for gastric cancer patients' stratification.
\end{abstract}

\title{
1. INTRODUCTION
}

Even more than four decades after declaring "war" on cancer at least 7 million patients die annually from the consequences of this disease, which represents $15 \%$ of all deaths worldwide $[\underline{1}, 2]$. Gastric cancer is globally the fifth most common cancer with near 1 million cases diagnosed in 2012 [3] and represents the third most common cause of cancer-related death. Due to its usually late diagnosis in already advanced stages it remains difficult to treat even in developed countries. Nowadays, there is no specific serological assay for the screening and diagnosis of gastric cancer, and endoscopy remains the gold standard in the clinical practice. However, the SLe ${ }^{a}$ glycan antigen CA19-9 is currently used for monitoring gastric cancer patients' response to treatment and recurrence [4, 5].

One of the most abundant forms of posttranslational modifications (PTM) of proteins is glycosylation, which is a complex process coordinated by the interplay of numerous glycosyltransferases and glycosidases, resulting in a vast diversity of structures. In cancer the disruption of the glycosylation machinery leads to aberrant expression of short truncated carbohydrate chains, known as cancer-associated simple carbohydrate antigens, and to altered expression of terminal sialylated chains $[6, z]$. These cancer-associated antigens are detected in 
different types of carcinomas and are associated with disease prognosis, constituting a pool of potential cancer biomarkers, especially when combined with information on the carrying proteins.

It has been long recognized that each cancer patient is different regarding prognosis, clinical presentation, tumor response and tolerance to treatment. With the constant improvement in sequencing and other large-scale analytical technologies, molecular tumor profiling has become unprecedentedly feasible [8]. This enables the identification of the unique combination of alterations, especially that of well-established cancer-related genes, for each patient and personalize their treatment. This customized attempt of tackling cancer has been on the focus of researchers for a long time, but for many cancer-associated alterations the understanding of the biological consequences and therapy-response implications lags behind [9].

One typical target of the personalized therapy strategies is the inhibition of activated signaling pathways, either by interfering directly with the receptor activation or interrupting the downstream signaling cascade by blocking specific GTPases [10]. Receptors such as EGFR, C-MET and RON (Recepteur d'Origine Nantais) can be targeted by small molecules or monoclonal antibodies that act as inhibitors by blocking ligand binding and signaling or by antibodies that tag tumor cells for immune response $[10,11]$. For instance, the RON receptor tyrosine kinase (also known as macrophage-stimulating protein receptor (MSPR) or $M_{S} T_{1}$ ) is constitutively transcribed in many epithelial cells but commonly shows aberrant activation in various tumors due to overexpression and generation of oncogenic variants. Currently several therapeutic agents and monoclonal antibodies targeting RON are tested in clinical and preclinical phases [12].

Therefore, two main goals in gastric cancer research are the discovery of new biomarkers for early diagnosis [5] and the elucidation of altered mechanisms that can be targeted for the development of novel directed and personalized treatments.

In the present work, we have performed a comprehensive analysis of cellular clones derived from MKN45 gastric carcinoma cells overexpressing the human $\alpha 2,3$-sialyltransferase ST3GAL4. The $N$ and $O$-glycomic, sialoproteomic and gene expression analysis were performed using a combination of high-throughput methods which revealed several cancer-associated glycomic alterations and generated a list of 47 putative glycoprotein targets with altered glycosylation in gastric cancer cells. Further characterization of one of the targets, the RON receptor tyrosine kinase, confirmed the altered glycosylation and revealed an increased activation of this oncogene in the gastric cancer cells. Finally, we demonstrate that this altered glycosylation of RON receptor tyrosine kinase occurs in human gastric tumors, showing that glycosylation alterations are an alternative pathway for cancer cells to activate receptors that lead to malignant growth, and which can be targets for personalized therapy in gastric cancer patients.

\section{MATERIALS AD METHODS}

\subsection{Cell culture:}

The gastric carcinoma cell line MKN45 was obtained from the Japanese Cancer Research Bank (Tsukuba, Japan) and was stably transfected with the full length human ST3GAL4 gene and the corresponding empty vector pcDNA3.1 (Mock) as previously shown [13]. The cells were grown in monolayer culture in uncoated cell culture flasks or cell culture flasks coated with fibronectin or 
collagen IV (BD BioCoat, BD Biosciences, Franklin Lakes, NJ). Cells were maintained at $37^{\circ} \mathrm{C}$ in an atmosphere of $5 \% \mathrm{CO}_{2}$ in RPMI 1640 GlutaMAX, HEPES medium supplemented with $10 \%$ fetal bovine serum (FBS), $1 \%$ penicillin-streptomycin and in the presence of $0.5 \mathrm{mg} / \mathrm{mL} \mathrm{G} 418$ (all from Invitrogen, Waltham, MA). Cell culture medium was replaced every two days.

\subsection{Quantitative real-time PCR (RT-PCR):}

Total RNA extracts from mock and $\mathrm{ST}_{3} \mathrm{GAL}_{4}$ transfected cell lysates were isolated with TRI Reagent (Sigma-Aldrich, St. Louis, MO) and converted into CDNA using the SuperScript ${ }^{\circledR}$ II Reverse Transcriptase (Invitrogen) according to the manufacturer's protocol. The following primers for $\mathrm{ST}_{3} \mathrm{GAL}_{4}$ were used applying the protocol previously described [13]: for $5^{\prime}$-cctggtagctttcaaggcaatg3'; rev5'-cctttcgcacccgcttct-3'. Expression level of 185 rRNA was used for mRNA expression normalization (for 5'-cgccgctagaggtgaaattc-3'; rev5'-cattcttggcaaatgctttcg-3').

\subsection{RNA Next Generation Sequencing:}

Total RNA was extracted as previously described in section 2.2. The mRNAs of over 20,000 primed targets were sequenced by using Ion AmpliSeq Transcriptome Human Gene Expression Kit. The Ion Chef system was used for templating and the loaded chips sequenced using the lon Proton System (both from Life Technologies). Sequencing data was automatically transfered to the dedicated Ion Torrent server to generate sequencing reads. Reads quality and trimming was performed using Torrent Server V4.2 before read aligment using TMAP 4.2. The TS plugin CoverageAnalysis V4.2 was used to generate reads count. The sequencing was performed in duplicates and sequence reads were normalized to the total read count.

\subsection{Immunofluorescence (IF):}

Cells were grown in $15 \mu$-Chamber 12 well glass slides (IBIDI, Martinsried, Germany) and either fixed with $4 \%$ paraformaldehyde (PFA) or cold acetone for 15 and $5 \mathrm{~min}$, respectively. The IF protocol performed was as previously described [13] using the antibodies and dilutions noted in table 1. Samples were examined under a Zeiss Imager.Z1 Axio fluorescence microscope (Zeiss, Welwyn Garden City, UK). Images were acquired using a Zeiss Axio cam MRm and the AxioVision Release 4.8.1 software.

\subsection{Protein and phosphoprotein arrays:}

Confluent cells were lysed in lysis buffer 17 or 6 (R\&D Systems, McKinley Place, MN) supplemented with $1 \mathrm{mM}$ sodium orthovanadate, $1 \mathrm{mM}$ phenylmethanesulfonylfluoride (PMSF) and protease inhibitor cocktail (Roche, Basel, Switzerland). The protein concentrations of lysates were determined by the DC protein assay (BioRad, Hercules, CA) and the recommended total protein amounts were used for the human non-haematopoietic soluble receptor array, human phosphoRTK array kit and human phospho-kinase array (R\&D Systems). The array protocols were performed according to manufacturer's instructions.

\subsection{Western (WB) and Lectin blotting (LB):}


Proteins were obtained from total cell lysates as previously described in section 2.5. Total lysates were denatured and charged using Laemmli buffer, separated by SDS-PAGE and blotted onto a nitrocellulose membrane (GE Healthcare, Chalfont, UK) in a semi-dry system (BioRad). Membranes were incubated with primary antibodies overnight at $4^{\circ} \mathrm{C}$ or with biotinylated lectins for $2 \mathrm{~h}$ at room temperature (Table 1). Secondary antibodies or avidin (ABC Standard Kit, Vector Laboratories, Burlingame, $C A$ ) conjugated with peroxidase were incubated for $1 \mathrm{~h}$ at room temperature. Target proteins were revealed by chemiluminescence using the ECL Western blotting detection reagent and films (both from GE Healthcare).

\subsection{In situ Proximity Ligation Assay (PLA):}

In situ Proximity Ligation Assay (PLA) was performed in acetone fixed cells as described in 2.4 or in paraffin sections from human gastric carcinoma tissues for the detection of co-expression in proximity of SLe ${ }^{x}$ and RON. PLA was performed adapting the procedure previously described [14 ]. Duolink II reagents (Olink Bioscience, Uppsala, Sweden) were used according to the manufacture instructions. Paraffin sections were dewaxed, rehydrated, antigen retrieval using sodium citrate buffer (10 mM, pH 6.0) was performed before sections were incubated with blocking solution (Olink Bioscience) for $30 \mathrm{~min}$ at $37^{\circ} \mathrm{C}$. Primary antibodies against SLe $e^{\mathrm{X}}$ and RON were used in equal concentrations as for IF (Table 1 ) and incubated overnight at $4^{\circ} \mathrm{C}$. Antibodies conjugated with oligonucleotides were utilized as secondary probes (DUO92001 and DUO92005 from Olink Bioscience). Ligation and amplification were performed at $37^{\circ} \mathrm{C}$ for $30 \mathrm{~min}$ or $120 \mathrm{~min}$ respectively and cell nuclei were visualized by DAPI (Sigma-Aldrich, $0.4 \mathrm{mg} / \mathrm{ml}$ ). Samples were examined under a Zeiss Imager.Z1 Axio fluorescence microscope (Zeiss, Welwyn Garden City, UK) equipped with DAPI, FITC and Texas Red filters. Proximity ligation assays products are seen as bright red fluorescent dots. Images were acquired using a Zeiss Axio cam MRm and the AxioVision Rel. 4.8 software. The resulting images were modified using ImageJ as follows: background with radius 5 was subtracted from the red channel of the RGB images and a multiply filter of 10 was applied. The result was intensity-scaled to suit printing demands.

\subsection{Immunohistochemistry (IHC):}

Tissue samples from gastric carcinoma patients were obtained from the archives of the Portuguese Institute of Oncology (IPO), Porto, Portugal. All procedures were performed after patient's written informed consent and approved by the local Ethical committee. All clinicopathological information was obtained from patients' clinical records. Expression of SLe ${ }^{\mathrm{X}}$ and RON were evaluated in 15 cases of human gastric carcinomas (10 cases of intestinal subtype and 5 cases of diffuse subtype according to Lauren's classification [15]). Paraffin sections were dewaxed, rehydrated and antigen retrieval was carried out by microwave treatment in sodium citrate buffer ( $10 \mathrm{mM}, \mathrm{pH} 6.0$ ) for 20 min. Endogenous peroxidases were blocked with $3 \%$ hydrogen peroxide $\left(\mathrm{H}_{2} \mathrm{O}_{2}\right)$ in methanol. Tissue sections were further blocked for 30 min with normal goat serum in PBS with $10 \%$ BSA, followed by incubation with primary antibodies against SLe $e^{\mathrm{X}}$ and RON (table 1 ) overnight at $4^{\circ} \mathrm{C}$. Biotin-labeled secondary antibodies (Dako, Glostrup, Denmark) were applied for $30 \mathrm{~min}$ and the $A B C$ kit (Vector Labs, Burlingame, CA) for $30 \mathrm{~min}$. Finally, sections were stained by $3,3^{\prime}$ diaminobenzidinetetrahydrochloride (DAB) and counterstained with Mayers' hematoxylin solution. Slides were examined using a Zeiss Optical Microscope.

\subsection{Sample preparation for LC-ESI-MS/MS and HILIC-FLD-UPLC analyses:}


Frozen cell pellets ( $10^{7}$ cells) were directly resuspended in $7 \mathrm{M}$ urea, $2 \mathrm{M}$ thiourea, $40 \mathrm{mM}$ Tris, $2 \%$ CHAPS, $10 \mathrm{mM}$ DTT and $1 \%$ protease inhibitor (Sigma-Aldrich, St. Louis, MO). The cell membranes were disrupted by 10 times $10 \mathrm{sec}$ sonication with 16 amplitudes and 1 minute on ice in between, and subsequent shaking at $4^{\circ} \mathrm{C}$ overnight. To reduce the viscosity of the lysates, the DNA was degraded by adding $1 \mu$ l benzonase ${ }^{\oplus}$ nuclease ( 250 units, Sigma-Aldrich) and 30 min incubation on $37^{\circ} \mathrm{C}$. In order to impair refolding of proteins, $25 \mathrm{mM}$ iodoacetamide were added for alkylation during $1 \mathrm{~h}$ in the dark. The lysates were centrifuged for $30 \mathrm{~min}$ with $14,000 \mathrm{rpm}$ and the supernatants transferred to a fresh tube.

Then, solubilized proteins were concentrated by adding $150 \mu \mathrm{l}$ of supernatant on a $10 \mathrm{kDa}$ cut-off spinfilter (PALL, Port Washington, NY), spinning down for 5 min with 12,000 $\times \mathrm{g}$ and washing 3 times with $100 \mu \mathrm{l} 50 \mathrm{mM} \mathrm{NH}_{4} \mathrm{HCO}_{3}, \mathrm{pH}$ 8.4. $\mathrm{N}$-linked oligosaccharides were released in the spinfilter using $20 \mu \mathrm{l} 50 \mathrm{mM} \mathrm{NH}_{4} \mathrm{HCO}_{3}$ and PNGase $\mathrm{F}\left(5 \mathrm{mU}\right.$, Prozyme, Hayward, $\mathrm{CA}$ ) with incubation at $37^{\circ} \mathrm{C}$ overnight. Subsequently, the $\mathrm{N}$-glycans were collected by washing 3 times with $20 \mu \mathrm{H}_{2} \mathrm{O}$ and dried in Speedvac. For UPLC analysis samples were further processed as described below and for LC-ESIMS/MS analysis samples were reduced with $0.5 \mathrm{M} \mathrm{NaBH}_{4} 10 \mathrm{mM} \mathrm{NaOH}$ at $50^{\circ} \mathrm{C}$ overnight. The $O$ linked glycans were released from retained glycoproteins in spinfilter using reductive $\beta$-elimination ( $0.5 \mathrm{M} \mathrm{NaBH}_{4} 50 \mathrm{mM} \mathrm{NaOH}$ at $50^{\circ} \mathrm{C}, 16 \mathrm{~h}$ ). Reactions were quenched with $1 \mu \mathrm{l}$ of glacial acetic acid and glycan (both $\mathrm{N}$-glycans and $\mathrm{O}$-glycans) samples were desalted and dried as previously described [16] and subjected to LC-ESI-MS/MS analysis.

\subsection{LC-ESI-MS/MS for $\mathrm{N}$ - and $\mathrm{O}$-glycomic analysis:}

Released glycans were analyzed by LC-ESI-MS/MS using a $10 \mathrm{~cm} \times 250 \mu \mathrm{m}$ I.D. column, prepared inhouse, containing $5 \mu \mathrm{m}$ porous graphitized carbon (PGC) particles (Thermo Scientific, Waltham, MA). Glycans were eluted using a linear gradient from o to $40 \%$ acetonitrile in $10 \mathrm{mM} \mathrm{NH}_{4} \mathrm{HCO}_{3}$ over $40 \mathrm{~min}$ at a flow rate of $10 \mu \mathrm{l} / \mathrm{min}$. The eluted $\mathrm{N}$ - and $\mathrm{O}$-glycans were detected using a LTO ion trap mass spectrometer (Thermo Scientific) in negative-ion mode with an electrospray voltage of $3.5 \mathrm{kV}$, capillary voltage of $-33.0 \mathrm{~V}$ and capillary temperature of $300^{\circ} \mathrm{C}$. Air was used as a sheath gas and mass ranges were defined dependent on the specific structure to be analyzed. The data were processed using the Xcalibur software (version 2.0.7, Thermo Scientific) and manually interpreted from their MS/MS spectra.

\subsection{Ultra performance liquid chromatography (UPLC):}

Released $\mathrm{N}$-glycans were labeled by reductive amination with the fluorophore 2-aminobenzamide (2-AB) (Sigma-Aldrich, St.Louis, MO) with sodium cyanoborohydride in $30 \% \mathrm{v} / \mathrm{v}$ acetic acid in DMSO at $65^{\circ} \mathrm{C}$ for $2 \mathrm{~h}$. Excess of $2-\mathrm{AB}$ reagent was removed on Glycoworks HILIC cartridges according to the manufacturer's instructions (Waters, Milford, MA) and then concentrated to dryness in speed-vac.

Hydrophilic interaction liquid chromatography (HILIC) of fluorescently labeled N-glycans was carried out on a $1.7 \mu \mathrm{m} \mathrm{BEH}$ glycan column (2.1 mm x $15 \mathrm{~mm}$, Waters, Milford, MA) and analyzed using Waters ACQUITY UPLC ${ }^{\circledR}$ I-class with fluorescence detection. The column temperature was kept at $40^{\circ} \mathrm{C}$ and the flow rate set to $0.561 \mathrm{~mL} / \mathrm{min}$ using a linear gradient of $50 \mathrm{mM}$ ammonium formate ( $\mathrm{pH} 4.4$ ) against acetonitrile with ammonium formate increasing from $30 \%$ to $47 \%$ over a 25 min period. An injection volume of $25 \mu \mathrm{L}$ sample prepared in $70 \% \mathrm{v} / \mathrm{v}$ acetonitrile was used




throughout. Fluorescence detection was achieved using excitation and emission wavelengths of 330 $\mathrm{nm}$ and $420 \mathrm{~nm}$, respectively.

The 2-AB labeled glycans were digested in $10 \mu \mathrm{L}$ of $50 \mathrm{mM}$ sodium phosphate, $\mathrm{pH} 6.0$ at $37^{\circ} \mathrm{C}$ overnight using sialidase $\mathrm{S}$ ( $4 \mathrm{mU}$, ProZyme) that releases $\alpha 2-3$ linked non-reducing terminal sialic acids (recombinant sialidase from Streptococcus pneumoniae, expressed in Escherichia coli) and sialidase A (5 mU, ProZyme) that releases $\alpha_{2-3 / 6 / 8}$ linked non-reducing terminal sialic acid (recombinant gene from Arthrobacter ureafaciens, expressed in Escherichia coli) to confirm sialic acid linkage. After incubation, enzymes were removed by filtration through a $10 \mathrm{kDa}$ cut-off spinfilter (PALL, Port Washington, NY) and the N-glycans were analysed by HILIC-FLD-UPLC. The system was calibrated by running an external standard of $2 \mathrm{AB}$-dextran ladder (2AB-glucose homopolymer, Ludger, Oxfordshire, UK) alongside the sample runs. A fifth-order polynomial distribution curve was fitted to the dextran ladder and used to allocate GU values from retention times (using Empower 3 software from Waters) [1]].

\subsection{Cell lysis, protein digestion and ITRAO labeling:}

Cell pellets were redissolved in ice-cold $\mathrm{Na}_{2} \mathrm{CO}_{3}$ buffer ( $0.1 \mathrm{M}, \mathrm{pH}$ 11) supplemented with protease inhibitor (Roche complete EDTA free), PhosSTOP phosphatase inhibitor cocktail (Roche) and 10 $\mathrm{mM}$ sodium pervanadate on ice. The suspensions were tip probe sonicated for $20 \mathrm{~s}$ (amplitude = $50 \%$ ) twice and incubated at $4^{\circ} \mathrm{C}$ for $\mathrm{Ih}$. The lysates were then centrifuged at $100,000 \times \mathrm{g}$ for $90 \mathrm{~min}$ at $4^{\circ} \mathrm{C}$ to separate soluble proteins from membrane proteins (pellet). The pellets were washed with $50 \mathrm{mM}$ triethylammonium bicarbonate (TEAB) to remove any remaining soluble protein. The supernatants containing soluble proteins were concentrated using $10 \mathrm{kDa}$ cutoff Amicon ultra centrifugal filters units (Millipore, Billerica, MA. USA) while membrane fractions were resuspended directly in $6 \mathrm{M}$ urea and $2 \mathrm{M}$ thiourea. Soluble and membrane fractions were both reduced in $10 \mathrm{mM}$ DTT for $30 \mathrm{~min}$ and then alkylated in $20 \mathrm{mM} \mathrm{IAA}$ for $30 \mathrm{~min}$ at room temperature in the dark.

Samples were incubated with endoproteinase Lys-C (Wako, Osaka, Japan) for 2 h (1:100 w/w). Following the incubation, the samples were diluted 8 times with $50 \mathrm{mM} \mathrm{TEAB}(\mathrm{pH} 8)$ and trypsin was added at a ratio of 1:50 (w/w) and left overnight at room temperature. Trypsin digestion was stopped by the addition of $2 \%$ formic acid and then the samples were centrifuged at $14,000 \times \mathrm{g}$ for $10 \mathrm{~min}$ to precipitate any lipids present in the sample. The supernatant was purified using in-house packed staged tips with a mixture of Poros $R_{2}$ and Oligo $R_{3}$ reversed phase resins (Applied Biosystem, Foster City, CA, USA). Briefly, a small plug of C18 material (3 M Empore) was inserted in the end of a P200 tips, followed by packing of the stage tip with the resins (resuspended in $100 \%$ ACN) by applying gentle air pressure. The acidified samples were loaded onto the micro-column after equilibration of the column with $0.1 \%$ trifluoroacetic acid (TFA), washed twice with $0.1 \%$ TFA and peptides were eluted with $60 \%$ ACN/o.1\% TFA. A small amount of purified peptides $(1 \mu \mathrm{l})$ from each sample was subjected to Qubit assay to determine the concentration, while the remaining samples were dried by vacuum centrifugation. Afterwards, peptides were redissolved in dissolution buffer and a total of $150 \mu \mathrm{g}$ for each condition was labeled with 4-plex TTRAO $^{\text {TM }}$ (Applied Biosystems, Foster (ity, CA) as described by the manufacturer. After labeling, the samples were mixed 1:1:1:1 and lyophilized by vacuum centrifugation.

\subsection{Sialic acid containing glycopeptide enrichment by TiSH protocol}


The method used for sialylated glycopeptides enrichment is a modification of the TiSH protocol [18] described in [19]. Briefly, samples were resuspended in loading buffer (1 M glycolic acid, 80\% ACN, $5 \%$ TFA) and incubated with $\mathrm{TiO}_{2}$ beads (GL Sciences, Japan, $10 \mu \mathrm{m}$; using a total of $0.6 \mathrm{mg} \mathrm{TiO}{ }_{2}$ beads per $100 \mu \mathrm{g}$ of peptides). The supernatant containing the unmodified peptides was carefully separated. The $\mathrm{TiO}_{2}$ beads were sequentially washed with loading buffer, washing buffer 1 (80\% ACN, $1 \%$ TFA) and washing buffer $2(20 \%$ ACN, $0.1 \%$ TFA), saving the washings with the previous supernatant. The bound peptides were eluted with 1.5\% ammonium hydroxide by shaking for 15 $\mathrm{min}$. The eluted fraction containing the phosphopeptides and sialylated glycopeptides was dried by vacuum centrifugation and subjected to an enzymatic deglycosylation in $20 \mathrm{mM}$ TEAB buffer using $500 \mathrm{U}$ of PNGase F (New England Biolabs, Ipswich, MA) and $0.1 \mathrm{U}$ of Sialidase A (Prozyme, Hayward, CA) overnight at $37^{\circ} \mathrm{C}$.

To separate phosphorylated peptides and formerly glycosylated peptides, the samples were subjected to a second $\mathrm{TiO}_{2}$ enrichment procedure to separate phosphorylated from deglycosylated peptides. The supernatant containing the deglycosylated peptides was saved and the beads were washed with $50 \%$ ACN, $0.1 \%$ TFA. The washing was added to the supernatant. The deglycosylated fraction was desalted on Oligo R3 staged tip column and dried prior to the HILIC fractionation [19]. All fractions were dried by vacuum centrifugation prior $\mathrm{nLC}-\mathrm{MS} / \mathrm{MS}$ analysis.

\subsection{Sialic acid containing glycopeptide analysis by nLC-MS/MS}

Samples were resuspended in $6 \mu \mathrm{L}$ of $0.1 \%$ TFA for analysis. Peptides were loaded on an in-house packed Reprosil-Pur C18-AO ( $2 \mathrm{~cm} \times 100 \mu \mathrm{m}, 5 \mu \mathrm{m}$; Dr. Maisch GmbH, Germany) pre-column and separated on an in-house packed Reprosil-Pur C18-AO (17 cm x $75 \mu \mathrm{m}, 3 \mu \mathrm{m}$; Dr. Maisch GmbH, Germany) column using an Easy-nLC II system (Thermo Scientific, Bremen, Germany) and eluted at a flow of $250 \mathrm{~nL} / \mathrm{min}$. Mobile phase was $95 \%$ acetonitrile (B) and water (A) both containing $0.1 \%$ formic acid. Depending on the samples, gradient was from $1 \%$ to $30 \%$ solvent $B$ in 80 or 110 min, 30 - $50 \%$ B in $10 \mathrm{~min}, 50-100 \%$ B in 5 min and 8 min at 100\% B. Mass spectrometric analyses were performed in an Orbitrap Fusion Tribrid system (Thermo Scientific, Bremen, Germany). MS scans $(400-1200 \mathrm{~m} / \mathrm{z})$ were acquired in the orbitrap at a resolution of 120000 at $200 \mathrm{~m} / \mathrm{z}$ for a AGC target of $5 \times 10^{5}$ ions and a maximum injection time of $60 \mathrm{~ms}$. Data-dependent HCD MS/MS analysis at top speed of the most intense ions were performed at a resolution of 30000 at $200 \mathrm{~m} / \mathrm{z}$ for a AGC target of $5 \times 10^{4}$ and a maximum injection time of $150 \mathrm{~ms}$ using the quadrupole to isolate the ions and an isolation window of $1.2 \mathrm{~m} / \mathrm{z}$, a NCE of $38 \%$ and a dynamic exclusion of $20 \mathrm{~s}$.

The raw data were processed and quantified by Proteome Discoverer (version 1.4.1.14, Thermo Scientific) against SwissProt and Uniprot human reference database by using Mascot (v2.3.02, Matrix Science Ltd, London, UK) and Sequest HT, respectively. Database searches were performed using the following parameters: precursor mass tolerance of $10 \mathrm{ppm}$, product ion mass tolerance of $0.02 \mathrm{Da}, 1$ missed cleavages for trypsin, carbamidomethylation of Cys and ITRAQ labelling on protein $\mathrm{N}$-terminal and Lys as fixed modifications, and phosphorylation on S/T/Y and deamidation of Asn as dynamic modifications. The ITRAO datasets were quantified using the centroid peak intensity with the "reporter ions quantifier" node. Only peptides with up to a q-value of 0.01 (Percolator), Mascot and Sequest HT rank 1, Sequest HT $\Delta$ Cn of 0.1, cut off value of Mascot score $\geq$ 18 and a cut-off value of XCorr score for charge states of $+1,+2,+3$, and +4 higher than $1.5,2,2.25$ and 2.5 , respectively, were considered for further analysis. 


\subsection{Data normalization and significance analysis}

Three biological replicates were analysed and submitted to the statistical analysis. The log 2 values of the measured intensities were normalized by the median. Modified peptides were merged with the R Rollup function (http://www.omics.pnl.gov) allowing for one-hit-wonders and using the mean of the normalized intensities for each peptide. Quantification of proteins was obtained by merging the un-modified peptides with the R Rollup function considering at least 2 unique peptides not allowing for one-hit-wonders and using the mean of the intensities. Then the mean over the experimental conditions for each peptide in each replicate was subtracted in order to merge data from different iTRAQ runs. Formerly sialylated glycopeptides containing the consensus motif for $\mathrm{N}$ linked glycosylation (NXS/T/C; where X \# P) were normalized based on the protein expression in each of the replicates. Significant up/down-regulations between experimental conditions were calculated allowing a false discovery rate of 0.05 . Therefore, we applied combined limma and rank product tests [20], subsequently corrected for multiple testing according to Storey.

Since spontaneous deamidation is frequently observed for asparagine residues, especially when the C-terminal amino acid is glycine (NG), the sites with NGS/T/C are considered as only potential glycosylation. However, in order to reduce the contribution from spontaneous deamidation in the final list, we sort first for the $\mathrm{N}$-linked consensus site (NXS/T/C) and then we filter for proteins that are membrane-associated in order to exclude intracellular proteins that are not $\mathrm{N}$-linked glycosylated.

\section{RESULTS}

\subsection{Overexpression of $\mathrm{ST}_{3} \mathrm{GAL}_{4}$ leads to increased expression of $\mathrm{SLe}^{\mathrm{X}}$}

The gastric cancer cell line MKN45 shows low expression levels of the sialyltransferase ST3GAL4 and of the terminal glycan epitope sialyl Lewis $X\left(S L e^{X}\right)[13]$. We have generated clones of MKN45 cells that were stably transfected with the full length $S T_{3} G A L_{4}$ resulting in approximately 150 times upregulation of this gene expression (Fig 1a). $\mathrm{ST}_{3} \mathrm{GAL}_{4}$ has been described to be upregulated in the context of gastric cancer and catalyzes the sialylation of Gal $\beta_{1-3}$ GalNAc on $O$-glycans and of type 2 (Galß1-4GlcNAc $\beta$-) extensions on both $N$ - and $O$-glycans, an intermediate epitope in the biosynthesis of SLe ${ }^{X}$ [21-23]. As a consequence of the increased expression of $\mathrm{ST}_{3} \mathrm{GAL}_{4}$, the terminal glycan epitope $\mathrm{SLe}^{\mathrm{X}}$ is overexpressed (Fig 1). Previous studies on this cell line have demonstrated increased invasive potential both in vitro and in vivo compared to the mock transfected control cell line [24]].

3.2 The $N$-glycome of $\mathrm{ST}_{3} \mathrm{GAL}_{4}$ overexpressing cells is specifically altered in $\alpha_{2}-6 / 3$ linked sialic acid content, bisecting and branched structures

To assess the full extent of glycomic alterations in our cell line model we performed a whole $\mathrm{N}$ glycomic analysis based on LC-ESI-MS/MS (Table 1 in [25]), to gain semi-quantitative and detailed structural information, and HILIC-FLD-UPLC for quantitative comparisons. The HILIC-FLD-UPLC spectra shows no alteration in the major peaks, which are of high-mannose nature and expectedly unaffected by alterations in sialyltransferase levels. This was confirmed by LC-ESI-MS/MS analysis 
(Fig $2 \mathrm{a}$ and 2b). Moreover, the total amount of sialylated structures was not significantly altered (Fig 2c). It should be noted that the structural analysis revealed also several truncated glycans (Table 1 in [25]) previously described in the $\mathrm{MKN}_{45}$ cell line as free $\mathrm{N}$-glycans [26]. Alterations in free $\mathrm{N}$-glycans are in conformity with their non-truncated equivalents and are thus not further described in this study.

Despite the overall similarity of the $\mathrm{N}$-glycome of cancer cells expressing $\mathrm{ST}_{3} \mathrm{GAL}_{4}$ and the control cell line, detailed analysis revealed several specific alterations in the cancer cells expressing $\mathrm{ST}_{3} \mathrm{GAL}_{4}$. Our results showed that the sialic acids linked $\alpha_{2}-6$ were reduced and the $\alpha_{2-3}$ linked reciprocally increased, indicating a shift of linkage in the ST3GAL4 transfected cells (Fig 3). Nevertheless, a2-6 linked sialic acid structures remain a large component of the ST3GallV cells' glycome. Since expression levels of sialyltransferases of the ST6 family are unaltered as shown by RNASeq (Supplementary table 1) we hypothesize that the observed isomeric change may be due to competition for the acceptor substrate.

Additionally, bisecting $\mathrm{N}$-glycan structures were significantly decreased (Fig 4). The presence of bisecting $N$-acetylglucosamine excludes the possibility of adding a $\beta_{1}-6$ branched arm to the complex $\mathrm{N}$-glycan and therefore often inversely correlates with the amount of large branched structures $[27,28]$. In our cancer cell line model, the amount of large and presumably branched complex $\mathrm{N}$-glycans is increased (Fig 4).

\section{3 $\mathrm{O}$-glycomic analysis reveals an increase in truncated $O$-glycans}

Mucin type $O$-glycosylation is commonly altered in cancer with truncation as the most common aberration [29]. MKN45, as a gastric epithelial derived cancer cell line, produces mainly core 20 glycans [30]. Our analyses showed high amounts of sialylated $O$-glycans in the MKN45 cell line with the majority of structures being decorated with at least one sialic acid (Table 3 in [25]). However, the overexpression of $\mathrm{ST}_{3} \mathrm{GAL}_{4}$ leads to an earlier termination by sialylation and thus, to the formation of truncated $O$-glycans ( $F i g$ ). This is mainly due to the increase in doubly sialylated core 2 structure which accounts for more than $40 \%$ of the total $O$-glycan amount in our transfected cells. On the other hand, $\mathrm{O}$-glycans composed of more than $2 \mathrm{~N}$-acetylhexosamines or hexoses were reduced by approximately $30 \%$ (Fig 5 ).

\subsection{Identification of over 40 glycoproteins with altered glycosylation}

The sialoproteomic analysis performed on protein extracts of ST3GAL4 and mock transfected cells revealed glycoproteins that display aberrant glycosylation. The analysis quantified 1566 unique glycopeptides of which 69 had a significantly altered abundance in sialylated $N$-glycosylation. Of those glycopeptides two showed a decrease in sialylation and the remaining 67 an increase in $S_{3} G A L 4$ transfected cells, corresponding to an overall total of 47 glycoproteins (Table 5 and 6 in [25]). Many of the identified glycoproteins have established functions in cellular signaling as either receptors or receptor interacting proteins, in cellular adhesion and migration, or are proteases (Fig 6). Among the identified glycoproteins, many well characterized targets that are described to be altered in the context of gastric carcinogenesis were found, such as Insulin receptor, CEACAM1, CEA, various Integrins and RON [12, 31-33].

.




\subsection{Activation of altered glycosylated RON receptor tyrosine kinase}

Given that the sialoproteomic analysis pointed out a potential alteration of the RON receptor tyrosine kinase glycosylation, we investigated this further, especially since this protein has been shown to be hyper-activated in the context of gastric cancer, contributing in tumorigenesis, malignant progression, angiogenesis, chemoresistance and correlating with bad prognosis [34-38]. Several mechanisms, including overexpression of this receptor and generation of oncogenic variants, have been described that can account for aberrant activation of RON, however, there are cases in which the cause for this abnormal activation remains unknown [38-40]. Comparative analysis between $\mathrm{ST}_{3} \mathrm{GAL}_{4}$ overexpressing cells and the mock transfected cells revealed that the expression of RON is unaltered at both RNA (Supplementary table 1) and protein levels (Fig 7), but shows around 4.5 times increased receptor activation in $\mathrm{ST}_{3} \mathrm{GAL}_{4}$ overexpressing cells (Fig $7 \mathrm{a}, \mathrm{b}$ ), as measured by the increase of phosphorylation of RON. The activated phosphorylated RON protein was observed on the plasma membrane coinciding with the expected localization of fully glycosylated RON (Fig 7c).

\subsection{Altered glycosylation of RON in gastric cancer}

In order to confirm the altered glycosylation of RON in the cell line model we used in situ proximity ligation assay (PLA). We demonstrated that RON is aberrantly glycosylated carrying the SLe ${ }^{x}$ epitope in ST3GAL4 transfected cells (Fig 8). The localization of RON receptor decorated with SLe ${ }^{\mathrm{X}}$ was observed in the cellular membrane. To assess whether the modification of RON occurs also in gastric carcinoma tissues we screened 15 human gastric tumor samples for the evaluation of the expression of RON and SLe ${ }^{\mathrm{X}}$. Of these 15 cases, 8 that showed expression of both antigens were further analyzed by PLA (Supplementary table 2). All evaluated cases showed PLA positivity signal with 2 cases displaying a high number of signal corresponding to co-expression in proximity of RON and SLe ${ }^{X}$. The tumor adjacent mucosa did not show any PLA signal and represents an internal control (Fig 8).

\section{DISCUSSION}

The altered glycosylation observed in gastric cancer with overexpression of $\alpha 2-3$ sialylated glycans, including the SLe ${ }^{x}$ epitope, has long been associated with aggressive features of the disease and poor prognosis for the patients $[5, \mathrm{Z}, 41-43]$. However, the biological role of these sialylated glycans remains to be fully understood. In this study, the detailed molecular characterization of gastric cancer cells displaying altered sialylated terminal glycan structures revealed how these glycosylation modifications can lead to functional changes that confer advantage to cancer cells.

\subsection{Glycosylation alterations induced by $\mathrm{ST}_{3} \mathrm{GAL}_{4}$ overexpression}

The sialyltransferase $\mathrm{ST}_{3} \mathrm{GAL}_{4}$, encoded by the $\mathrm{ST}_{3} \mathrm{GAL}_{4}$ gene, catalyzes the addition of $\alpha_{2}$-3-sialic acid to type 2 extension chains (Gal $\left.\beta_{1,4} \mathrm{GlNNAC}_{1}-\mathrm{R}\right)$ generating the precursor of $\operatorname{SLe}^{\mathrm{X}}[13, \underline{21}]$. In our study we demonstrated that the overexpression of $\mathrm{ST}_{3} \mathrm{GAL}_{4}$, in accordance to its substrate 
specificity, leads to a broad range of glycomic alterations on both $\mathrm{N}$ - and $\mathrm{O}$-glycans. Importantly, $\mathrm{ST}_{3} \mathrm{GAL}_{4}$ overexpression induces the expression of SLe ${ }^{\mathrm{x}}$ which has been described to be commonly upregulated in gastric cancer $[41,44,45]$. Further, we demonstrated for the first time in a gastric cancer context that the upregulation of $\mathrm{ST}_{3} \mathrm{GAL}_{4}$, an $\alpha 2-3$ sialyltransferase, not only increases the amount of $\alpha_{2-3}$ linked sialic acid, but as a consequence, reduces the amount of $\alpha_{2}-6$-linked sialic acid expressed by the cancer cell, as it has been previously reported in a pancreatic cancer cell line model [46]. The expression levels of other sialyltransferases remained unaltered (Supplementary table 1) supporting the assumption that this linkage-shift is rooted in competition for the same asialylated substrate. Although the general amount of sialylated glycans is described to increase in the context of transformation and malignancy [47, 48], it is known that the linkage type is of particular importance. Interestingly, the upregulation of $\alpha 2-6$ sialylation has been shown to increase the adhesion of colon and breast cancer cells to extra cellular matrix components and to reduce the invasive capacity of colon and glioma cancer cell lines [49-51]. Similarly, the increased invasive capacity of $\mathrm{ST}_{3} \mathrm{GAL}_{4}$ overexpressing cells previously described [24] could also result from the reduction of $\alpha 2-6$ linked sialic acid modified structures.

Our results also showed an almost complete loss of all bisected $\mathrm{N}$-glycan structures in cancer cells overexpressing $\mathrm{ST}_{3} \mathrm{GAL}_{4}$. A correlation between sialylation and the activity of GnT-III, the GIcNActransferase that leads to the synthesis of bisected $\mathrm{N}$-glycans, has to our knowledge never been reported. Sialyltransferases are normally located in the trans-Golgi and the sialylation resembles a capping event for mature complex and hybrid N-glycans [52], on the other hand the GnT-III is localized in the medial-Golgi and acts early on the biosynthesis of complex N-glycans [53]. It is important to consider that the subcellular localization of glycosyltransferases and the organization of the secretory compartments are often altered in the context of cancer [54] and this may lead to deviations of the conventional sequential biosynthesis pathway. Moreover, it is known that bisected structures are often reduced in malignancy and this reduction is correlated with tumor progression and poorer prognosis $[27,55,56]$. Our results showed that $N$-glycans from ST3GAL4 transfected cells display a higher degree of branching resulting in enlargement and increased complexity of structures. In addition, no differences were observed on GnT-V, which is the GlcNAc-transferase that catalyzes the formation of $\beta_{1}-6$ branched $N$-glycans, and GnT-III expression levels (Supplementary table 1 ). These enzymes are known to act mutually exclusive on their common glycan acceptor substrate $[\underline{28}, 53,56]$, and therefore the increased branched $\mathrm{N}$-glycans could stem from the reduced amount of bisected structures.

Regarding $O$-glycosylation, we demonstrated that $\mathrm{ST}_{3} \mathrm{GAL}_{4}$ upregulation can also lead to the increased truncation of otherwise elongated $O$-glycans. The accumulation of short truncated $O$ glycans like simple carbohydrate antigens are a common feature of gastrointestinal cancer [57]. Our results show that the biosynthesis of early sialylated core-2 structures preclude further elongation of the $O$-glycan chain.

Our data indicates, for the first time, that several cancer relevant glycomic alterations, such as truncation of $O$-glycans, reduction of bisected $N$-glycans, increase of $\alpha 2-3$ sialylation and branching, might not be independent events but may arise coordinated in gastric cancer. The observed changes were further confirmed in an additional glycomic analysis performed in parallel (Tables 2 and 4 in $[25])[58,59]$. These glycophenotypic alterations may result from genetic and epigenetic alterations, as well as from tumor microenvironment modifications, occurring in the cancer context [60-63]. 


\subsection{Target proteins displaying aberrant sialylation and its biological implications}

In addition, our results revealed that even though the total amount of sialylated $\mathrm{N}$-glycans is not significantly increased, 47 glycoproteins showed significantly increased sialylation in a site specific manner in $\mathrm{ST}_{3} \mathrm{GAL}_{4}$ overexpressing cancer cells. Considering that only proteins that are translated into the ER are $\mathrm{N}$-glycosylated and that only those proteins that are conveyed through the Golginetwork undergo addition of sialic acids [64], it is not surprising that especially transmembrane proteins were found to be affected by the increased sialylation. Furthermore, an interesting observation is that mainly proteins involved in cellular adherence and signaling were affected by this altered glycosylation. Important targets included key players in malignancy, such as Integrins, which are known to mediate the interaction of cancer cells to the extracellular matrix [33]. Integrin glycosylation has been shown to modulate the cell adhesion to fibronectin and to affect cancer cell invasion and metastasis [65].

In this study we only considered for validation unique peptide sequences that contained $\mathrm{N}$ glycosylation sites. The majority of enriched peptides, due to increased sialylation on $O$-glycans or due to common amino acid sequences, were excluded from the analysis. With our approach we could not distinguish between sialic acid linkage and therefore the generation of information of glycopeptides with specific increases of $\alpha 2-3$ sialic acids was precluded. Nonetheless, our approach allowed to identify numerous targets showing altered glycosylation that can be used for follow-up studies. Further, it illustrates that alterations of a single glycosyltransferases can affect a multitude of cancer relevant targets.

\subsection{Receptor glycosylation as a modulator of activity in cancer}

Receptor tyrosine kinases are glycoproteins and key players of transformation and malignant growth [66]. Glycosylation alterations have been demonstrated to modulate receptor activity [24, 67 6 68]. In the present study we have focused on the alterations leading to the receptor RON activation. In the last years several efforts have been made to target RON in cancer patients. Currently several tyrosine kinase inhibitors and monoclonal antibodies against RON are applied in clinical or pre-clinical trials for therapeutic efficacy [69-76]. Our screening revealed that this receptor, which has been described to be an oncogene in gastric cancer [12], showed an altered glycosylation and concomitant increased activation. RON presents 3 immunoglobulin-like plexin and transcription (IPT) domains that have been described as a cause for constitutive activation in cancer when altered [39, 27]. We demonstrated that Asn841 shows increased sialylation in cells overexpressing ST3GAL4 (Table 5 in [25]). The Asn841 is located in one of the IPT domains and therefore may underlie the increased activation of this cellular RTK. Further analysis by proximity ligation assay confirmed the glycosylation of RON with SLe ${ }^{X}$ in human gastric carcinoma tissues. These observations support that the altered glycosylation observed in this receptor in gastric cancer may lead to its dysfunctional oncogenic activation and therefore modulating the more aggressive cancer phenotype associated with SLe ${ }^{x}$ expressing tumors. Further studies are warranted to evaluate the biomarker potential of RON glycosylation profile for gastric cancer staging, prognosis and therapeutic response.

\subsection{Potential application in cancer therapy and future outlook}


Hyper-activation of RTKs due to their upregulation or mutations are common oncogenic events that modern medicine tries to evaluate in the process of tumor screening to design a personalized treatment via inhibitors [9]. However, the present screening methods mostly rely on identifying mutations or gene amplifications [78, 79]; and therefore not considering post-translational modifications, such as glycosylation, as potential activators in a cancer context. We demonstrated in this work that aberrant glycosylation is an alternative route of RTK activation in cancer, emphasizing the necessity for its evaluation in tumor characterization and patient profiling.

A common drawback of whole glycome analysis is its intrinsic complexity, delaying its application in the clinical routine. Much has to be done to simplify and standardize such glycome analysis and to improve our understanding of glycosylation alterations on specific targets. However, the present work demonstrates the importance of such approaches in addressing complex diseases in combination with large scale genomics, transcriptomics and proteomics. We are convinced that the screening of specific target proteins for glycan alterations can be a future corner stone of clinical tumor characterization complementing the conventional methods and therefore leading to improved molecular characterization of cancers for a better diagnosis, prognosis and therapeutics.

\section{ACKNOWLEDGEMENTS}

We acknowledge the support from the European Union, Seventh Framework Programme, Gastric Glyco Explorer initial training network: grant number 316929. IPATIMUP integrates the i3S Research Unit, which is partially supported by FCT, the Portuguese Foundation for Science and Technology. This work is funded by FEDER funds through the Operational Programme for Competitiveness Factors-COMPETE (FCOMP-01-0124-FEDER028188) and National Funds through the FCT-Foundation for Science and Technology, under the projects: PEst-C/SAU/LA0003/2013, PTDC/BBB-EBI/0786/2012, PTDC/BBB-EBI/0567/2014 (to CAR). This work was also supported by "Glycoproteomics" project grant number PCIGog-GA-2011-293847 (to DK) and the Danish Natural Science Research Council and a generous grant from the VILLUM Foundation to the VILLUM Center for Bioanalytical Sciences at the University of Southern Denmark (to MRL). Grants were received from FCT, POPH (Programa Operacional Potencial Humano) and FSE (Fundo Social Europeu): SFRH/BPD/75871/2011 to AM; SFRH/BPD/111048/2015 to JAF; SFRH/BPD/96510/2013 to CG. The UPLC instrument was obtained with a grant from the Ingabritt and Arne Lundbergs Research Foundation. C.J. was supported by the Knut and Alice Wallenberg Foundation. The mass spectrometer (LTQ) was obtained by a grant from the Swedish Research Council (342-2004-4434). 


\section{REFERENCES}

[1] R.L. Siegel, K.D. Miller, A. Jemal, Cancer statistics, 2015, CA: a cancer journal for clinicians, 65 (2015) 5-29.

[2] M. May, Statistics: Attacking an epidemic, Nature, 509 (2014) S50-51.

[3] J. Ferlay, E. Steliarova-Foucher, J. Lortet-Tieulent, S. Rosso, J.W. Coebergh, H. Comber, D. Forman, F. Bray, Cancer incidence and mortality patterns in Europe: estimates for 40 countries in 2012, European journal of cancer, 49 (2013) 1374-1403.

[4] M. Carpelan-Holmstrom, J. Louhimo, U.H. Stenman, H. Alfthan, C. Haglund, CEA, CA 19-9 and CA 72-4 improve the diagnostic accuracy in gastrointestinal cancers, Anticancer research, 22 (2002) 2311-2316.

[5] C.A. Reis, H. Osorio, L. Silva, C. Gomes, L. David, Alterations in glycosylation as biomarkers for cancer detection, Journal of clinical pathology, 63 (2010) 322-329.

[6] A. Varki, R. Kannagi, B.P. Toole, Glycosylation Changes in Cancer, in: A. Varki, R.D. Cummings, J.D. Esko, H.H. Freeze, P. Stanley, C.R. Bertozzi, G.W. Hart, M.E. Etzler (Eds.) Essentials of Glycobiology, Cold Spring Harbor (NY), 2009.

[7] S.S. Pinho, C.A. Reis, Glycosylation in cancer: mechanisms and clinical implications, Nature reviews. Cancer, 15 (2015) 540-555.

[8] K.M. Wong, T.J. Hudson, J.D. McPherson, Unraveling the genetics of cancer: genome sequencing and beyond, Annual review of genomics and human genetics, 12 (2011) 407-430.

[9] R.L. Schilsky, Personalized medicine in oncology: the future is now, Nature reviews. Drug discovery, 9 (2010) 363-366.

[10] C. Sawyers, Targeted cancer therapy, Nature, 432 (2004) 294-297.

[11] A. Arora, E.M. Scholar, Role of tyrosine kinase inhibitors in cancer therapy, The Journal of pharmacology and experimental therapeutics, 315 (2005) 971-979.

[12] H.P. Yao, Y.Q. Zhou, R. Zhang, M.H. Wang, MSP-RON signalling in cancer: pathogenesis and therapeutic potential, Nature reviews. Cancer, 13 (2013) 466-481.

[13] A.S. Carvalho, A. Harduin-Lepers, A. Magalhaes, E. Machado, N. Mendes, L.T. Costa, R. Matthiesen, R. Almeida, J. Costa, C.A. Reis, Differential expression of alpha-2,3-sialyltransferases and alpha-1,3/4-fucosyltransferases regulates the levels of sialyl Lewis a and sialyl Lewis $\mathrm{x}$ in gastrointestinal carcinoma cells, The international journal of biochemistry \& cell biology, 42 (2010) 8o-89. 
[14] T. Conze, A.S. Carvalho, U. Landegren, R. Almeida, C.A. Reis, L. David, O. Soderberg, MUC2 mucin is a major carrier of the cancer-associated sialyl-Tn antigen in intestinal metaplasia and gastric carcinomas, Glycobiology, 20 (2010) 199-206.

[15] P. Lauren, The Two Histological Main Types of Gastric Carcinoma: Diffuse and So-Called Intestinal-Type Carcinoma. An Attempt at a Histo-Clinical Classification, Acta pathologica et microbiologica Scandinavica, 64 (1965) 31-49.

[16] B.L. Schulz, N.H. Packer, N.G. Karlsson, Small-scale analysis of O-linked oligosaccharides from glycoproteins and mucins separated by gel electrophoresis, Analytical chemistry, 74 (2002) 60886097 .

[17] L. Royle, C.M. Radcliffe, R.A. Dwek, P.M. Rudd, Detailed structural analysis of N-glycans released from glycoproteins in SDS-PAGE gel bands using HPLC combined with exoglycosidase array digestions, Methods in molecular biology, 347 (2006) 125-143.

[18] K. Engholm-Keller, P. Birck, J. Storling, F. Pociot, T. Mandrup-Poulsen, M.R. Larsen, TiSH--a robust and sensitive global phosphoproteomics strategy employing a combination of TiO2, SIMAC, and HILIC, Journal of proteomics, 75 (2012) 5749-5761.

[19] M.N. Melo-Braga, M. Ibanez-Vea, M.R. Larsen, K. Kulej, Comprehensive protocol to simultaneously study protein phosphorylation, acetylation, and $\mathrm{N}$-linked sialylated glycosylation, Methods in molecular biology, 1295 (2015) 275-292.

[20] V. Schwammle, I.R. Leon, O.N. Jensen, Assessment and improvement of statistical tools for comparative proteomics analysis of sparse data sets with few experimental replicates, Journal of proteome research, 12 (2013) 3874-3883.

[21] A. Harduin-Lepers, M.A. Krzewinski-Recchi, F. Colomb, F. Foulquier, S. Groux-Degroote, P. Delannoy, Sialyltransferases functions in cancers, Frontiers in bioscience, 4 (2012) 499-515.

[22] K. Sasaki, E. Watanabe, K. Kawashima, S. Sekine, T. Dohi, M. Oshima, N. Hanai, T. Nishi, M. Hasegawa, Expression cloning of a novel Gal beta (1-3/1-4) GlcNAc alpha 2,3-sialyltransferase using lectin resistance selection, The Journal of biological chemistry, 268 (1993) 22782-22787.

[23] H. Kitagawa, J.C. Paulson, Cloning of a novel alpha 2,3-sialyltransferase that sialylates glycoprotein and glycolipid carbohydrate groups, The Journal of biological chemistry, 269 (1994) 1394-1401.

[24] C. Gomes, H. Osorio, M.T. Pinto, D. Campos, M.J. Oliveira, C.A. Reis, Expression of ST3GAL4 leads to $\mathrm{SLe}(\mathrm{x})$ expression and induces c-Met activation and an invasive phenotype in gastric carcinoma cells, PloS one, 8 (2013) e66737.

[25] S. Mereiter, A. Magalhães, B. Adamczyk, C. Jin, A. Almeida, L. Drici, M. Ibanez-Vea, M.R. Larsen, D. Kolarich, N.G. Karlsson, C.A. Reis, Glycomic and sialoproteomic data of gastric carcinoma cells overexpressing ST3GAL4, Data in Brief, (Submitted). 
[26] A. Ishizuka, Y. Hashimto, R. Naka, M. Kinoshita, K. Kakehi, J. Seino, Y. Funakoshi, T. Suzuki, A. Kameyama, H. Narimatsu, Accumulation of free complex-type N-glycans in MKN7 and MKN 45 stomach cancer cells, The Biochemical journal, 413 (2008) 227-237.

[27] S.S. Pinho, C.A. Reis, J. Paredes, A.M. Magalhaes, A.C. Ferreira, J. Figueiredo, W. Xiaogang, F. Carneiro, F. Gartner, R. Seruca, The role of N-acetylglucosaminyltransferase III and V in the posttranscriptional modifications of E-cadherin, Human molecular genetics, 18 (2009) 2599-2608.

[28] Y. Zhao, T. Nakagawa, S. Itoh, K. Inamori, T. Isaji, Y. Kariya, A. Kondo, E. Miyoshi, K. Miyazaki, N. Kawasaki, N. Taniguchi, J. Gu, N-acetylglucosaminyltransferase III antagonizes the effect of Nacetylglucosaminyltransferase $\mathrm{V}$ on alphazbeta1 integrin-mediated cell migration, The Journal of biological chemistry, 281 (2006) 32122-32130.

[29] M.R. Kudelka, T. Ju, J. Heimburg-Molinaro, R.D. Cummings, Simple sugars to complex disease-mucin-type O-glycans in cancer, Advances in cancer research, 126 (2015) 53-135.

[30] Y. Rossez, E. Maes, T. Lefebvre Darroman, P. Gosset, C. Ecobichon, M. Joncquel Chevalier Curt, I.G. Boneca, J.C. Michalski, C. Robbe-Masselot, Almost all human gastric mucin O-glycans harbor blood group $\mathrm{A}, \mathrm{B}$ or $\mathrm{H}$ antigens and are potential binding sites for Helicobacter pylori, Glycobiology, 22 (2012) 1193-1206.

[31] C. Boccaccio, P.M. Comoglio, Invasive growth: a MET-driven genetic programme for cancer and stem cells, Nature reviews. Cancer, 6 (2006) 637-645.

[32] N. Beauchemin, A. Arabzadeh, Carcinoembryonic antigen-related cell adhesion molecules (CEACAMs) in cancer progression and metastasis, Cancer metastasis reviews, 32 (2013) 643-671.

[33] J.S. Desgrosellier, D.A. Cheresh, Integrins in cancer: biological implications and therapeutic opportunities, Nature reviews. Cancer, 10 (2010) 9-22.

[34] M.H. Wang, W. Lee, Y.L. Luo, M.T. Weis, H.P. Yao, Altered expression of the RON receptor tyrosine kinase in various epithelial cancers and its contribution to tumourigenic phenotypes in thyroid cancer cells, The Journal of pathology, 213 (2007) 402-411.

[35] M.N. Thobe, D. Gurusamy, P. Pathrose, S.E. Waltz, The Ron receptor tyrosine kinase positively regulates angiogenic chemokine production in prostate cancer cells, Oncogene, 29 (2010) 214-226.

[36] J. Logan-Collins, R.M. Thomas, P. Yu, D. Jaquish, E. Mose, R. French, W. Stuart, R. McClaine, B. Aronow, R.M. Hoffman, S.E. Waltz, A.M. Lowy, Silencing of RON receptor signaling promotes apoptosis and gemcitabine sensitivity in pancreatic cancers, Cancer research, 70 (2010) 1130-1140.

[37] R.J. McClaine, A.M. Marshall, P.K. Wagh, S.E. Waltz, Ron receptor tyrosine kinase activation confers resistance to tamoxifen in breast cancer cell lines, Neoplasia, 12 (2010) 650-658.

[38] D.V. Catenacci, G. Cervantes, S. Yala, E.A. Nelson, E. El-Hashani, R. Kanteti, M. El Dinali, R. Hasina, J. Bragelmann, T. Seiwert, M. Sanicola, L. Henderson, T.A. Grushko, O. Olopade, T. Karrison, Y.J. Bang, W.H. Kim, M. Tretiakova, E. Vokes, D.A. Frank, H.L. Kindler, H. Huet, R. Salgia, 
RON (MST1R) is a novel prognostic marker and therapeutic target for gastroesophageal adenocarcinoma, Cancer biology \& therapy, 12 (2011) 9-46.

[39] C. Collesi, M.M. Santoro, G. Gaudino, P.M. Comoglio, A splicing variant of the RON transcript induces constitutive tyrosine kinase activity and an invasive phenotype, Molecular and cellular biology, 16 (1996) 5518-5526.

[40] M.M. Santoro, C. Collesi, S. Grisendi, G. Gaudino, P.M. Comoglio, Constitutive activation of the RON gene promotes invasive growth but not transformation, Molecular and cellular biology, 16 (1996) 7072-7083.

[41] M. Amado, F. Carneiro, M. Seixas, H. Clausen, M. Sobrinho-Simoes, Dimeric sialyl-Le(x) expression in gastric carcinoma correlates with venous invasion and poor outcome, Gastroenterology, 114 (1998) 462-470.

[42] R. Kannagi, Carbohydrate-mediated cell adhesion involved in hematogenous metastasis of cancer, Glycoconjugate journal, 14 (1997) 577-584.

[43] S. Nakamori, M. Kameyama, S. Imaoka, H. Furukawa, O. Ishikawa, Y. Sasaki, Y. Izumi, T. Irimura, Involvement of carbohydrate antigen sialyl Lewis(X) in colorectal cancer metastasis, Diseases of the colon and rectum, 40 (1997) 420-431.

[44] M. Tatsumi, A. Watanabe, H. Sawada, Y. Yamada, Y. Shino, H. Nakano, Immunohistochemical expression of the sialyl Lewis $x$ antigen on gastric cancer cells correlates with the presence of liver metastasis, Clinical \& experimental metastasis, 16 (1998) 743-750.

[45] S.E. Baldus, T.K. Zirbes, S.P. Monig, S. Engel, E. Monaca, K. Rafiqpoor, F.G. Hanisch, C. Hanski, J. Thiele, H. Pichlmaier, H.P. Dienes, Histopathological subtypes and prognosis of gastric cancer are correlated with the expression of mucin-associated sialylated antigens: Sialosyl-Lewis(a), SialosylLewis $(x)$ and sialosyl-Tn, Tumour biology : the journal of the International Society for Oncodevelopmental Biology and Medicine, 19 (1998) 445-453.

[46] M. Perez-Garay, B. Arteta, E. Llop, L. Cobler, L. Pages, R. Ortiz, M.J. Ferri, C. de Bolos, J. Figueras, R. de Llorens, F. Vidal-Vanaclocha, R. Peracaula, alpha2,3-Sialyltransferase ST3Gal IV promotes migration and metastasis in pancreatic adenocarcinoma cells and tends to be highly expressed in pancreatic adenocarcinoma tissues, The international journal of biochemistry \& cell biology, 45 (2013) 1748-1757.

[47] Y.J. Kim, A. Varki, Perspectives on the significance of altered glycosylation of glycoproteins in cancer, Glycoconjugate journal, 14 (1997) 569-576.

[48] F. Dall'Olio, M. Chiricolo, Sialyltransferases in cancer, Glycoconjugate journal, 18 (2001) 841850.

[49] S. Lin, W. Kemmner, S. Grigull, P.M. Schlag, Cell surface alpha 2,6 sialylation affects adhesion of breast carcinoma cells, Experimental cell research, 276 (2002) 101-110. 
[50] H. Yamamoto, A. Oviedo, C. Sweeley, T. Saito, J.R. Moskal, Alpha2,6-sialylation of cell-surface $\mathrm{N}$-glycans inhibits glioma formation in vivo, Cancer research, 61 (2001) 6822-6829.

[51] M. Chiricolo, N. Malagolini, S. Bonfiglioli, F. Dall'Olio, Phenotypic changes induced by expression of beta-galactoside alpha2, 6 sialyltransferase $I$ in the human colon cancer cell line SW948, Glycobiology, 16 (2006) 146-154.

[52] R. Kornfeld, S. Kornfeld, Assembly of asparagine-linked oligosaccharides, Annual review of biochemistry, 54 (1985) 631-664.

[53] N. Taniguchi, Y. Ihara, Recent progress in the molecular biology of the cloned Nacetylglucosaminyltransferases, Glycoconjugate journal, 12 (1995) 733-738.

[54] S. Kellokumpu, R. Sormunen, I. Kellokumpu, Abnormal glycosylation and altered Golgi structure in colorectal cancer: dependence on intra-Golgi pH, FEBS letters, 516 (2002) 217-224.

[55] Y. Song, J.A. Aglipay, J.D. Bernstein, S. Goswami, P. Stanley, The bisecting GlcNAc on Nglycans inhibits growth factor signaling and retards mammary tumor progression, Cancer research, 70 (2010) 3361-3371.

[56] S.S. Pinho, P. Oliveira, J. Cabral, S. Carvalho, D. Huntsman, F. Gartner, R. Seruca, C.A. Reis, C. Oliveira, Loss and recovery of Mgat3 and GnT-III Mediated E-cadherin N-glycosylation is a mechanism involved in epithelial-mesenchymal-epithelial transitions, PloS one, 7 (2012) e33191.

[57] S. Hakomori, Aberrant glycosylation in tumors and tumor-associated carbohydrate antigens, Advances in cancer research, 52 (1989) 257-331.

[58] P.H. Jensen, N.G. Karlsson, D. Kolarich, N.H. Packer, Structural analysis of N- and O-glycans released from glycoproteins, Nature protocols, 7 (2012) 1299-1310.

[59] D. Kolarich, M. Windwarder, K. Alagesan, F. Altmann, Isomer-Specific Analysis of Released NGlycans by LC-ESI MS/MS with Porous Graphitized Carbon, Methods in molecular biology, 1321 (2015) 427-435.

[6o] C. Slawson, G.W. Hart, O-GlcNAc signalling: implications for cancer cell biology, Nature reviews. Cancer, 11 (2011) 678-684.

[61] F. Alisson-Silva, L. Freire-de-Lima, J.L. Donadio, M.C. Lucena, L. Penha, J.N. Sa-Diniz, W.B. Dias, A.R. Todeschini, Increase of O-glycosylated oncofetal fibronectin in high glucose-induced epithelial-mesenchymal transition of cultured human epithelial cells, PloS one, 8 (2013) e60471.

[62] S. Olivier-Van Stichelen, C. Guinez, A.M. Mir, Y. Perez-Cervera, C. Liu, J.C. Michalski, T. Lefebvre, The hexosamine biosynthetic pathway and O-GlcNAcylation drive the expression of betacatenin and cell proliferation, American journal of physiology. Endocrinology and metabolism, 302 (2012) E417-424. 
[63] Z. Ma, D.J. Vocadlo, K. Vosseller, Hyper-O-GlcNAcylation is anti-apoptotic and maintains constitutive NF-kappaB activity in pancreatic cancer cells, The Journal of biological chemistry, 288 (2013) 15121-15130.

[64] P. Stanley, Golgi glycosylation, Cold Spring Harbor perspectives in biology, 3 (2011).

[65] J. Gu, N. Taniguchi, Regulation of integrin functions by N-glycans, Glycoconjugate journal, 21 (2004) 9-15.

[66] D. Hanahan, R.A. Weinberg, Hallmarks of cancer: the next generation, Cell, 144 (2011) 646-674.

[67] K. Kaszuba, M. Grzybek, A. Orlowski, R. Danne, T. Rog, K. Simons, U. Coskun, I. Vattulainen, NGlycosylation as determinant of epidermal growth factor receptor conformation in membranes, Proceedings of the National Academy of Sciences of the United States of America, 112 (2015) 43344339.

[68] A. Cazet, S. Julien, M. Bobowski, J. Burchell, P. Delannoy, Tumour-associated carbohydrate antigens in breast cancer, Breast cancer research : BCR, 12 (2010) 204.

[69] T.K. Choueiri, U. Vaishampayan, J.E. Rosenberg, T.F. Logan, A.L. Harzstark, R.M. Bukowski, B.I. Rini, S. Srinivas, M.N. Stein, L.M. Adams, L.H. Ottesen, K.H. Laubscher, L. Sherman, D.F. McDermott, N.B. Haas, K.T. Flaherty, R. Ross, P. Eisenberg, P.S. Meltzer, M.J. Merino, D.P. Bottaro, W.M. Linehan, R. Srinivasan, Phase II and biomarker study of the dual MET/VEGFR2 inhibitor foretinib in patients with papillary renal cell carcinoma, Journal of clinical oncology : official journal of the American Society of Clinical Oncology, 31 (2013) 181-186.

[70] A. Belalcazar, D. Azana, C.A. Perez, L.E. Raez, E.S. Santos, Targeting the Met pathway in lung cancer, Expert review of anticancer therapy, 12 (2012) 519-528.

[71] Y. Zhang, P.J. Kaplan-Lefko, K. Rex, Y. Yang, J. Moriguchi, T. Osgood, B. Mattson, A. Coxon, M. Reese, T.S. Kim, J. Lin, A. Chen, T.L. Burgess, I. Dussault, Identification of a novel recepteur d'origine nantais/c-met small-molecule kinase inhibitor with antitumor activity in vivo, Cancer research, 68 (2008) 6680-6687.

[72] S. Sharma, J.Y. Zeng, C.M. Zhuang, Y.Q. Zhou, H.P. Yao, X. Hu, R. Zhang, M.H. Wang, Smallmolecule inhibitor BMS-777607 induces breast cancer cell polyploidy with increased resistance to cytotoxic chemotherapy agents, Molecular cancer therapeutics, 12 (2013) 725-736.

[73] B.S. Pan, G.K. Chan, M. Chenard, A. Chi, L.J. Davis, S.V. Deshmukh, J.B. Gibbs, S. Gil, G. Hang, H. Hatch, J.P. Jewell, I. Kariv, J.D. Katz, K. Kunii, W. Lu, B.A. Lutterbach, C.P. Paweletz, X. Qu, J.F. Reilly, A.A. Szewczak, Q. Zeng, N.E. Kohl, C.J. Dinsmore, MK-2461, a novel multitargeted kinase inhibitor, preferentially inhibits the activated c-Met receptor, Cancer research, 70 (2010) 1524-1533.

[74] A.B. Northrup, M.H. Katcher, M.D. Altman, M. Chenard, M.H. Daniels, S.V. Deshmukh, D. Falcone, D.J. Guerin, H. Hatch, C. Li, W. Lu, B. Lutterbach, T.J. Allison, S.B. Patel, J.F. Reilly, M. Reutershan, K.W. Rickert, C. Rosenstein, S.M. Soisson, A.A. Szewczak, D. Walker, K. Wilson, J.R. Young, B.S. Pan, C.J. Dinsmore, Discovery of 1-[3-(1-methyl-1H-pyrazol-4-yl)-5-0xo-5H- 
benzo[4,5]cyclohepta[1,2-b]pyridin-7-yl] -N-(pyridin-2-ylmethyl)methanesulfonamide (MK-8033): A Specific c-Met/Ron dual kinase inhibitor with preferential affinity for the activated state of c-Met, Journal of medicinal chemistry, 56 (2013) 2294-2310.

[75] J.M. O'Toole, K.E. Rabenau, K. Burns, D. Lu, V. Mangalampalli, P. Balderes, N. Covino, R. Bassi, M. Prewett, K.J. Gottfredsen, M.N. Thobe, Y. Cheng, Y. Li, D.J. Hicklin, Z. Zhu, S.E. Waltz, M.J. Hayman, D.L. Ludwig, D.S. Pereira, Therapeutic implications of a human neutralizing antibody to the macrophage-stimulating protein receptor tyrosine kinase (RON), a c-MET family member, Cancer research, 66 (2006) 9162-9170.

[76] Z. Gunes, A. Zucconi, M. Cioce, A. Meola, M. Pezzanera, S. Acali, I. Zampaglione, V. De Pratti, L. Bova, F. Talamo, A. Demartis, P. Monaci, N. La Monica, G. Ciliberto, A. Vitelli, Isolation of Fully Human Antagonistic RON Antibodies Showing Efficient Block of Downstream Signaling and Cell Migration, Translational oncology, 4 (2011) 38-46.

[77] O. Ma, K. Zhang, S. Guin, Y.Q. Zhou, M.H. Wang, Deletion or insertion in the first immunoglobulin-plexin-transcription (IPT) domain differentially regulates expression and tumorigenic activities of RON receptor Tyrosine Kinase, Molecular cancer, 9 (2010) 307.

[78] M. Ingelman-Sundberg, Personalized medicine into the next generation, Journal of internal medicine, 277 (2015) 152-154.

[79] T. Tursz, R. Bernards, Hurdles on the road to personalized medicine, Molecular oncology, 9 (2015) 935-939.

[80] N. Shibuya, I.J. Goldstein, W.F. Broekaert, M. Nsimba-Lubaki, B. Peeters, W.J. Peumans, The elderberry (Sambucus nigra L.) bark lectin recognizes the Neu5Ac(alpha 2-6)Gal/GalNAc sequence, The Journal of biological chemistry, 262 (1987) 1596-1601. 


\section{FIGURES}

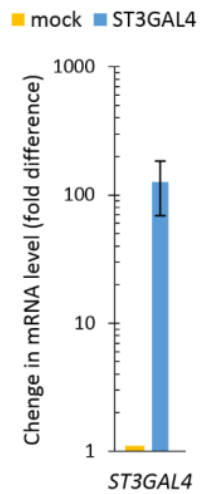

B
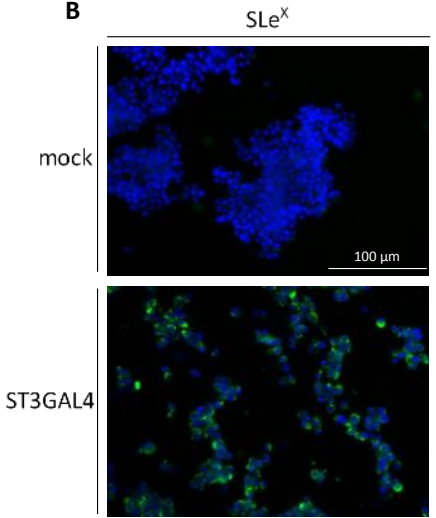

C

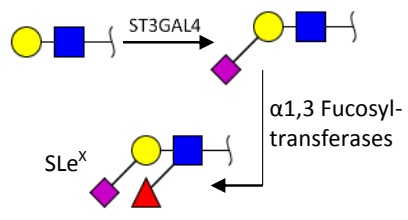

Gal, Galactose

Figure 1. Gastric carcinoma cell line overexpressing $\mathrm{ST}_{3} \mathrm{GAL}_{4}$ shows upregulation of $\mathrm{SLe}^{\mathrm{X}}$ expression

A. Relative quantification of $\mathrm{ST}_{3} G A L_{4}$ mRNA expression using quantitative real-time PCR. MKN45 cells transfected with $\mathrm{ST}_{3} \mathrm{GAL}_{4}$ show an approximately 150 times increase when compared with mock transfected MKN45 cells. Values were based on quadruplicates of cell lines. Results are presented as average \pm SD.

B. Cells that overexpress $\mathrm{ST}_{3} \mathrm{GAL}_{4}$ display an increased expression of the $\mathrm{SLe}^{\mathrm{x}}$ epitope as shown by immunofluorescence using anti-SLe $\mathrm{X}^{\mathrm{X}}$ antibody (KM93).

C. Depiction of the addition of $\alpha 2-3$ sialic acid to Galß1-4GICNAc, which is the major reaction that is catalyzed by the sialyltransferase $\mathrm{ST}_{3} \mathrm{GAL}_{4}$ as previously described [18]. The glycan structure $\mathrm{Gal}_{\beta_{1}-}$ 4 GlcNAc is commonly found in both $\mathrm{N}$ - and $\mathrm{O}$-glycans and is referred to as type 2 chain. This structure can be further fucosylated leading to an increase of the $S L e^{X}$ glycan epitope. 

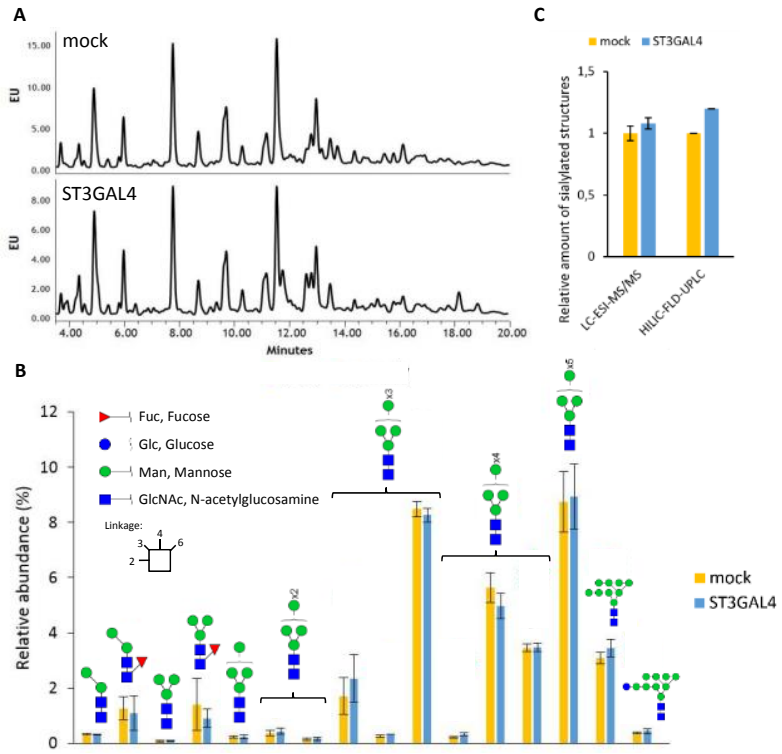

Figure 2. The overall $\mathrm{N}$-glycome of $\mathrm{ST}_{3} \mathrm{GAL}_{4}$ overexpressing cells is largely unaltered A. The quantitative HILIC-FLD-UPLC chromatograms of 2AB labeled N-glycans show highly similar $N$ glycan profiles of $\mathrm{ST}_{3} G A L_{4}$ transfected and control cell line. EU: Emission unit.

B. Relative quantification of high mannose structures reveals that the expression of this group of $\mathrm{N}$ glycans is unaffected when compared between $\mathrm{ST}_{3} \mathrm{GAL}_{4}$ overexpressing cells and the mock transfected control. $\mathrm{N}$-glycans were quantified by evaluating base-peak intensity of extracted ion chromatograms from LC-ESI-MS and were performed in three biological replicates. Values are presented as average \pm SD.

C. Quantification of the relative amount of sialylated $\mathrm{N}$-glycan structures by LC-ESI-MS and HILICFLD-UPLC shows no significant increase when comparing sialyltransferase $\mathrm{ST}_{3} \mathrm{GAL}_{4}$ overexpressing cells with mock control. 


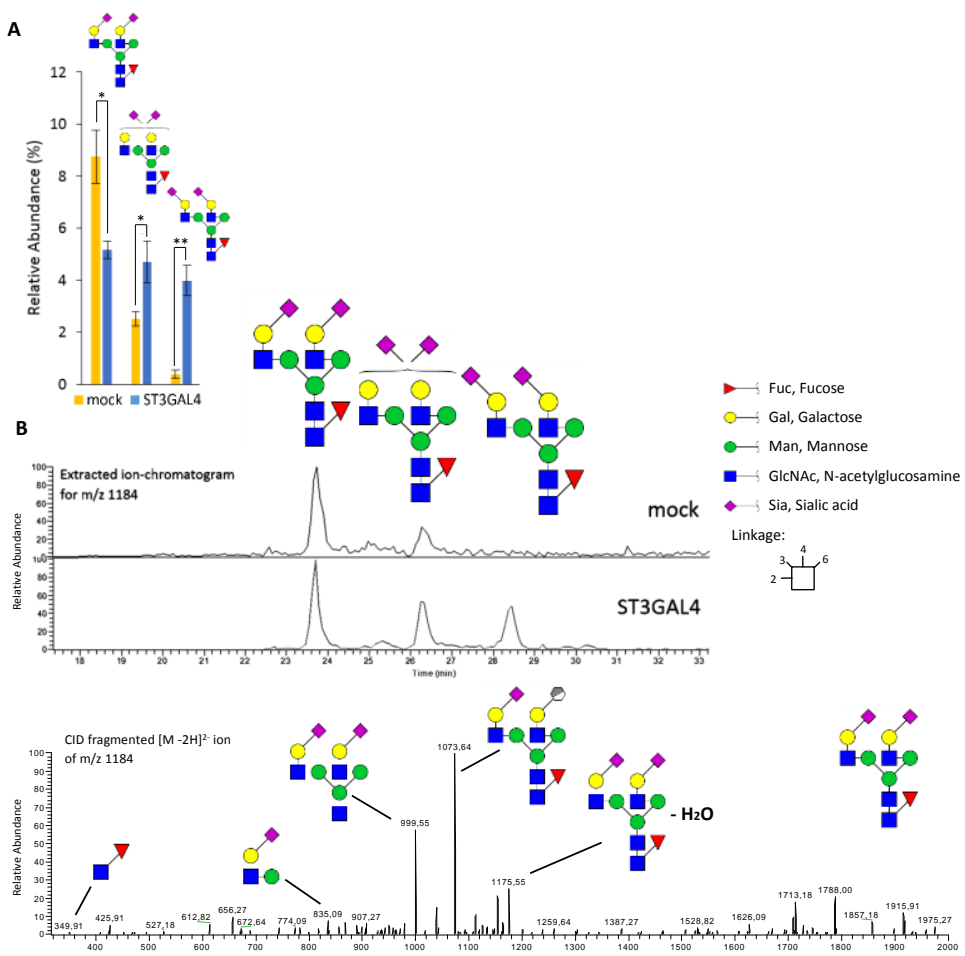

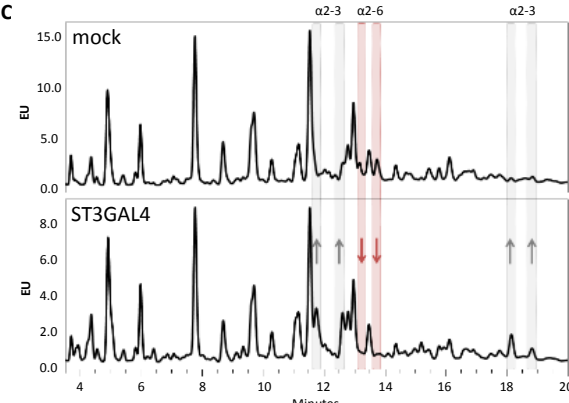

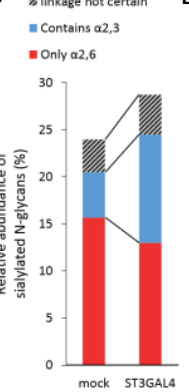

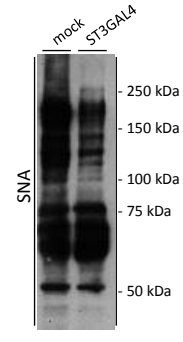

Figure 3. Sialylation of $N$-glycans in $\mathrm{ST}_{3} \mathrm{GAL}_{4}$ overexpressing cells shows a shift from $\alpha_{2}-6$ linked towards $\alpha 2-3$ linked

A. Relative quantification of disialylated biantennary structures illustrates the general trend that $\alpha_{2}-6$ linked sialic acids are reduced whereas $\alpha 2-3$ linked are increased. The quantifications are established by base-peak intensity of extracted ion chromatograms from LC-ESI-MS performed in three biological replicates and presented as average \pm SD. Statistical significance was determined by unpaired student's t-test ( $\mathrm{p}$-value $*<0.05 ; * *<0.01$ ).

B. Extracted ion-chromatogram for $\mathrm{m} / \mathrm{z} 1184$ shows the relative increase of disialylated biantennary structures with $\alpha 2-3$ linked sialic acids when compared to $\alpha 2-6$ linked. Structures were assigned by a combination of $\mathrm{MS}^{2}$ spectra (shown below) and $\alpha 2-3$ specific sialidase treatment.

C, D. Quantitative HILIC-FLD-UPLC of 2-AB labeled $N$-glycans confirm that $\alpha 2-3$ carrying species are increased and $\alpha_{2}-6$ are decreased in $S T_{3} G A L_{4}$ compared to mock transfected cells. Sialic acid linkage was determined by Sialidase A (releases $\alpha_{2}-3,6,8$ ) and Sialidase $S$ (releases $\alpha_{2}-3$ ) sialidase treatment experiments. EU: Emission unit.

E. Sambucus nigra (SNA, binds $\alpha 2-6$ linked sialic acid) lectin blot reveals that especially proteins in the higher molecular mass area (>75 kDa) are significantly less decorated with $\alpha 2,6$-linked sialic acid. 
A

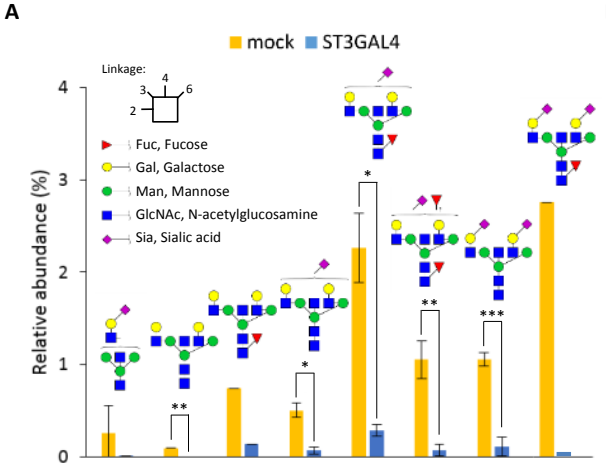

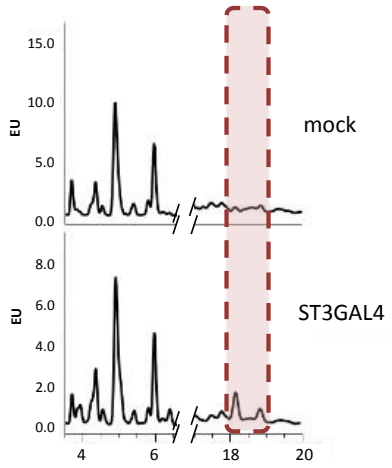

C

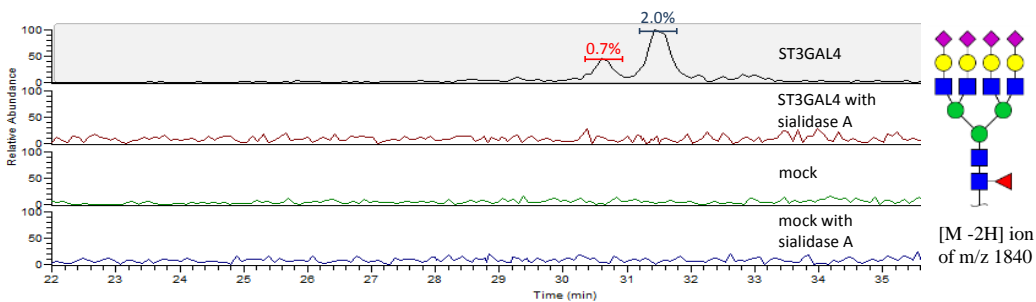

Figure 4. Bisecting structures are significantly reduced and large branched $N$-glycans are increased in $\mathrm{ST}_{3} \mathrm{GAL}_{4}$ overexpressing cells

A. Quantification of relative abundance of bisecting structures shows significant reduction of all examined structures. The glycans were quantified with base-peak intensity of extracted ion chromatograms from LC-ESI-MS performed in three biological replicates. Statistical significance was determined by unpaired student's t-test ( $p$-value $*<0.05 ; * *<0.01 ; * * *<0.001$ ).

B. The $N$-glycan HILIC-FLD-UPLC data reveals an increase in very large, putative highly branched, $\alpha 2-$ 3 sialylated $N$-glycans (framed area) in $\mathrm{ST}_{3} \mathrm{GAL}_{4}$ overexpressing cells. These structures correspond to approximately $4 \%$ of the total $N$-glycome. EU: emission units.

C. Core fucosylated, tetrasialylated, tetraantennary structures (depicted on the right side) are very abundant in $\mathrm{ST}_{3} \mathrm{GAL}_{4}$ overexpressing cells but are not detectable in the mock control as shown by extracted ion chromatogram of $[\mathrm{M}-2 \mathrm{H}]$ ion of $\mathrm{m} / \mathrm{z} 1840$. The two peaks in the upper panel correspond to isomers of the depicted structure. Annotation is based on fragmentation spectra and glycosidase digestion experiments. Relative amount was determined by base-peak intensity and is shown above the corresponding peaks. 

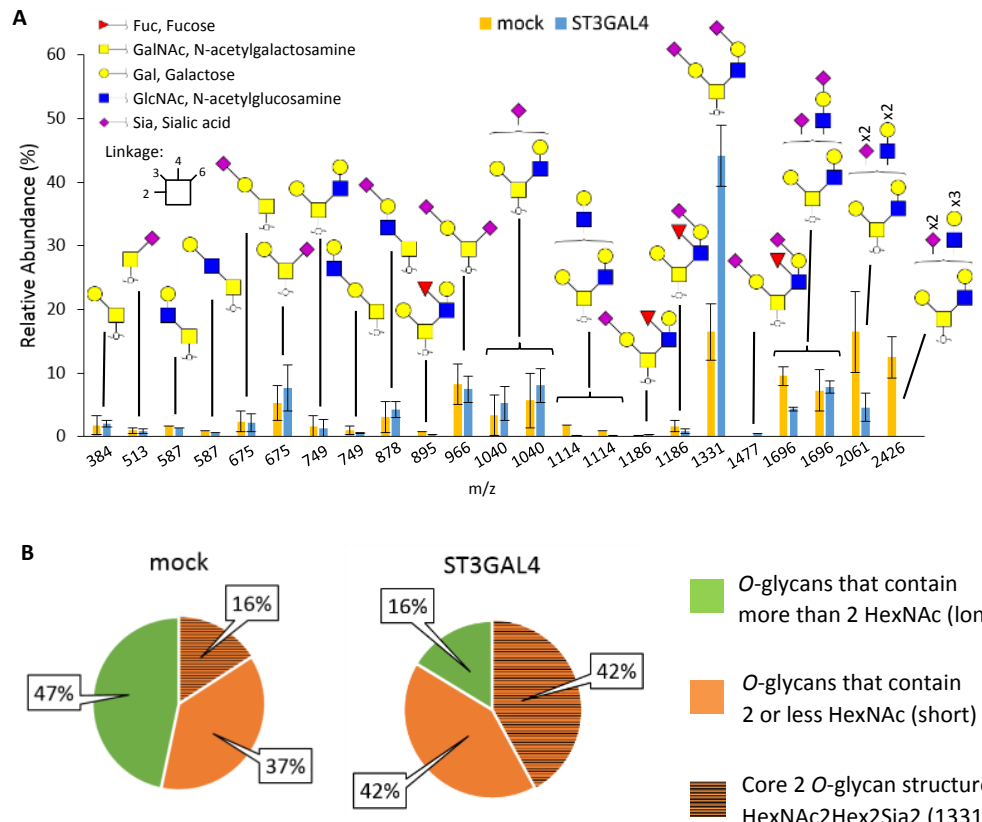

$O$-glycans that contain more than 2 HexNAc (long)

$O$-glycans that contain 2 or less HexNAc (short)

Core $2 \mathrm{O}$-glycan structure HexNAc2Hex2Sia2 (1331 m/z)

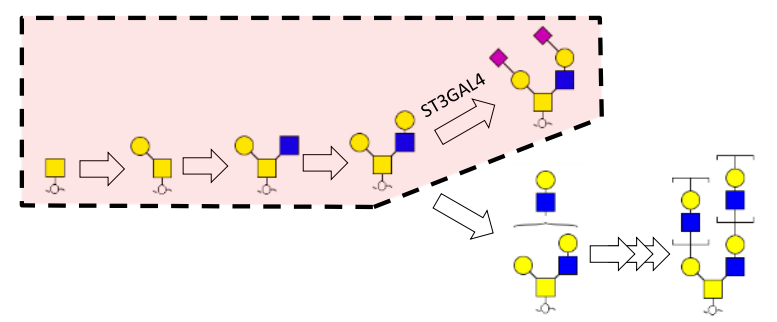

Figure 5. Increase in disialylated core 2 structures in $\mathrm{ST}_{3} \mathrm{GAL}_{4}$ overexpressing cells leads to earlier termination and thus truncation of $O$-glycan structures

A. Relative abundance of all structurally characterized $O$-glycan compounds. Diagram is ordered from left to right by mass. Simple $O$-glycan residues show no significant alteration. Terminated unextended disialylated core 2 structures $[\mathrm{M}-\mathrm{H}]$ ion of $\mathrm{m} / \mathrm{z} 1331$ are significantly increased and as a consequence extended structures are reduced in $\mathrm{ST}_{3} \mathrm{GAL}_{4}$ overexpressing cells. The quantifications are established by base-peak intensity of extracted ion chromatograms from LC-ESI-MS performed in three biological replicates and presented as average \pm SD.

B. Pie-diagram illustrates the approximately equal distribution of short and long $O$-glycans in mock transfected $\mathrm{MKN}_{45}$ cells, and the truncation that is observed in $\mathrm{ST}_{3} \mathrm{GAL}_{4}$ overexpressing cells. $O$ glycans with less than or equal 2 HexNAc or Hex were considered short $O$-glycans, structures with 3 or more HexNAcs or Hex were considered long $O$-glycans. The abundance of the simple disialylated core 2 structure (NeuAc2 Hex2HexNAc2) is highlighted in dashed orange

C. Schematic representation of the impact of $\mathrm{ST}_{3} \mathrm{GAL}_{4}$ overexpression on the biosynthesis of $O$ -

glycan in MKN45. The frame indicates the preferred pathway in the ST3GAL4 transfected cell line. 


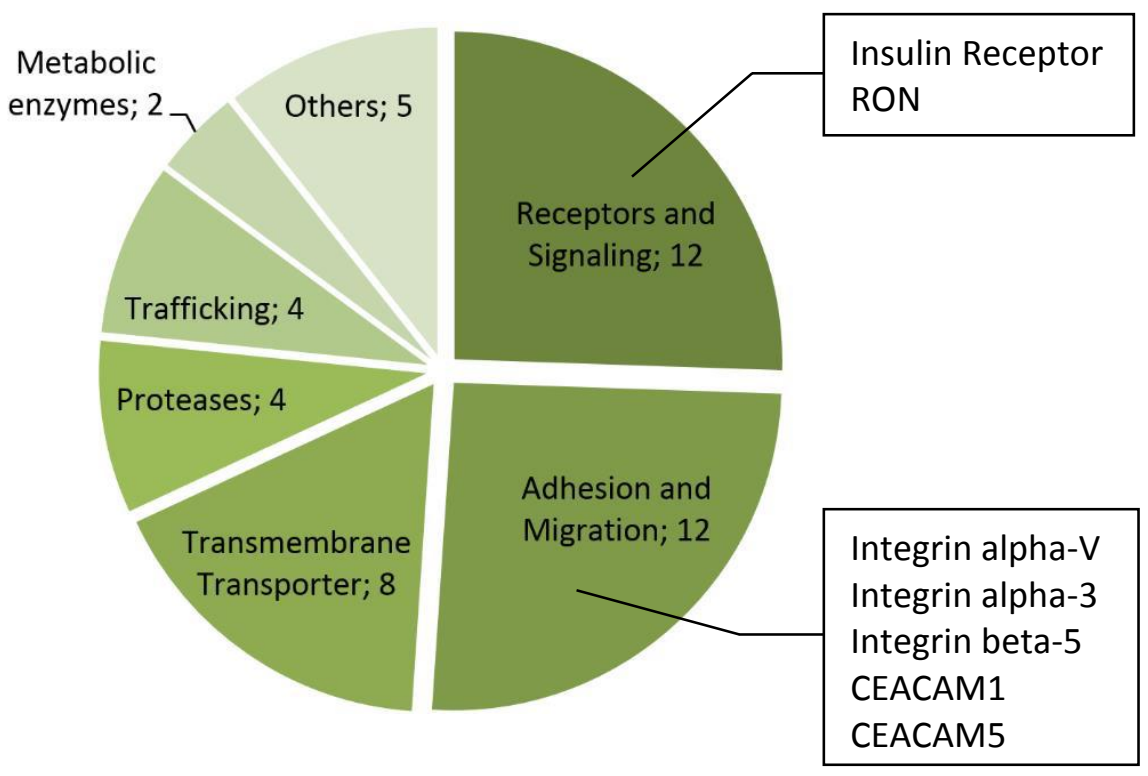

Figures 6 . Representation of the biological functions of the proteins identified with increased sialylation on their N-glycans in ST3GAL4 transfected cells

Functional clustering reveals that most of the proteins found with increased sialylated $\mathrm{N}$-glycans are involved in signaling, adhesion and migration processes. Remarkably many of these targets have been described to be often altered in gastric cancer. The 47 proteins with significantly increased sialylation were classified according to their main function described in Uniprot (www.uniprot.org). 
A mock $\square$ ST3GAL4

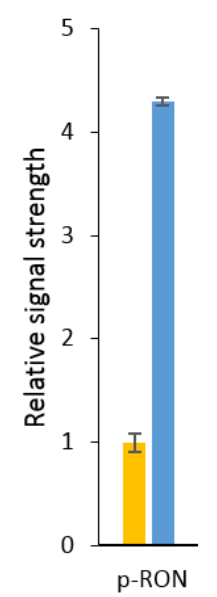

B

$150 \mathrm{kDa}$
C
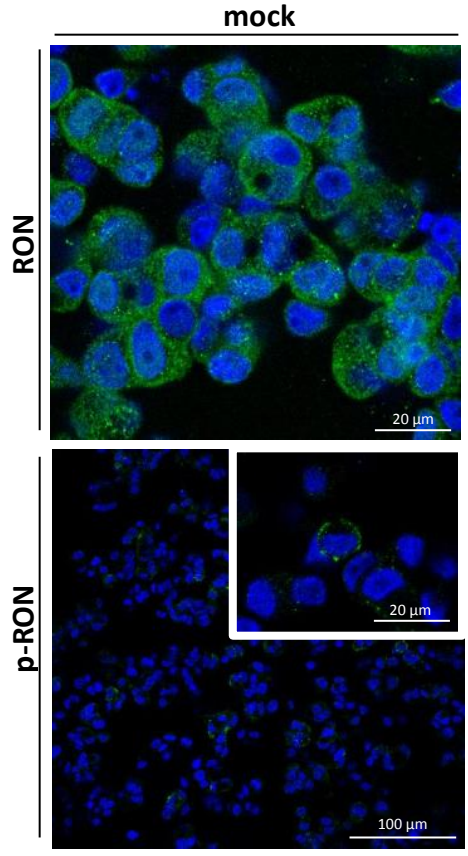

ST3GAL4
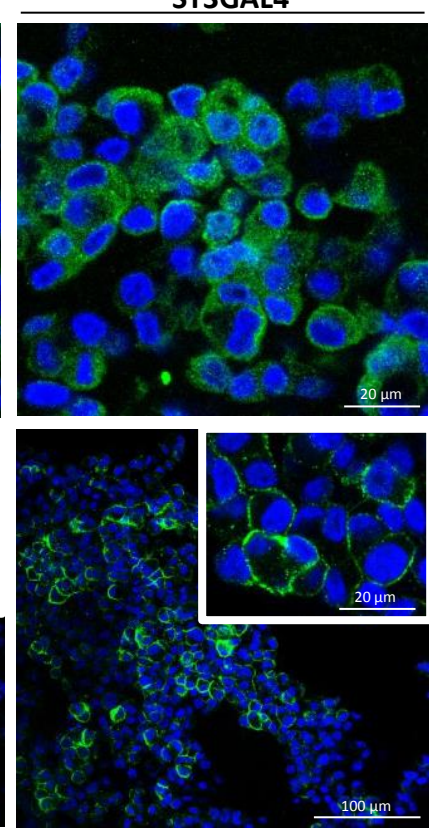

Figure 7. Receptor tyrosine kinase RON is activated in $\mathrm{ST}_{3} \mathrm{GAL}_{4}$ overexpressing cells

A. RON shows approximately 4.5 fold increased activation in $\mathrm{ST}_{3} \mathrm{GAL}_{4}$ overexpressing cells as indicated by phospho-RTK array results. The optical density of $\mathrm{p}-\mathrm{RON}$ signal was measured in duplicates. Average values, with standard deviation are shown. The receptor activation of $S_{3} G A L 4$ transfected cells is shown relative to the mock control cells.

B. Western blot for RON and phosphorylated RON (p-RON) confirms the increased phosphorylation of RON in ST3GAL4 overexpressing cells and shows no difference in total RON receptor amount.

C. Immunofluorescence images of cells stained for RON show cytoplasmic and membrane localization of the receptor with similar amounts for both, ST3GAL4 transfected and control cell lines. In contrast, activated RON is localized at the plasma membrane and strongly increased in cells overexpressing $\mathrm{ST}_{3} \mathrm{GAL}_{4}$. 
A

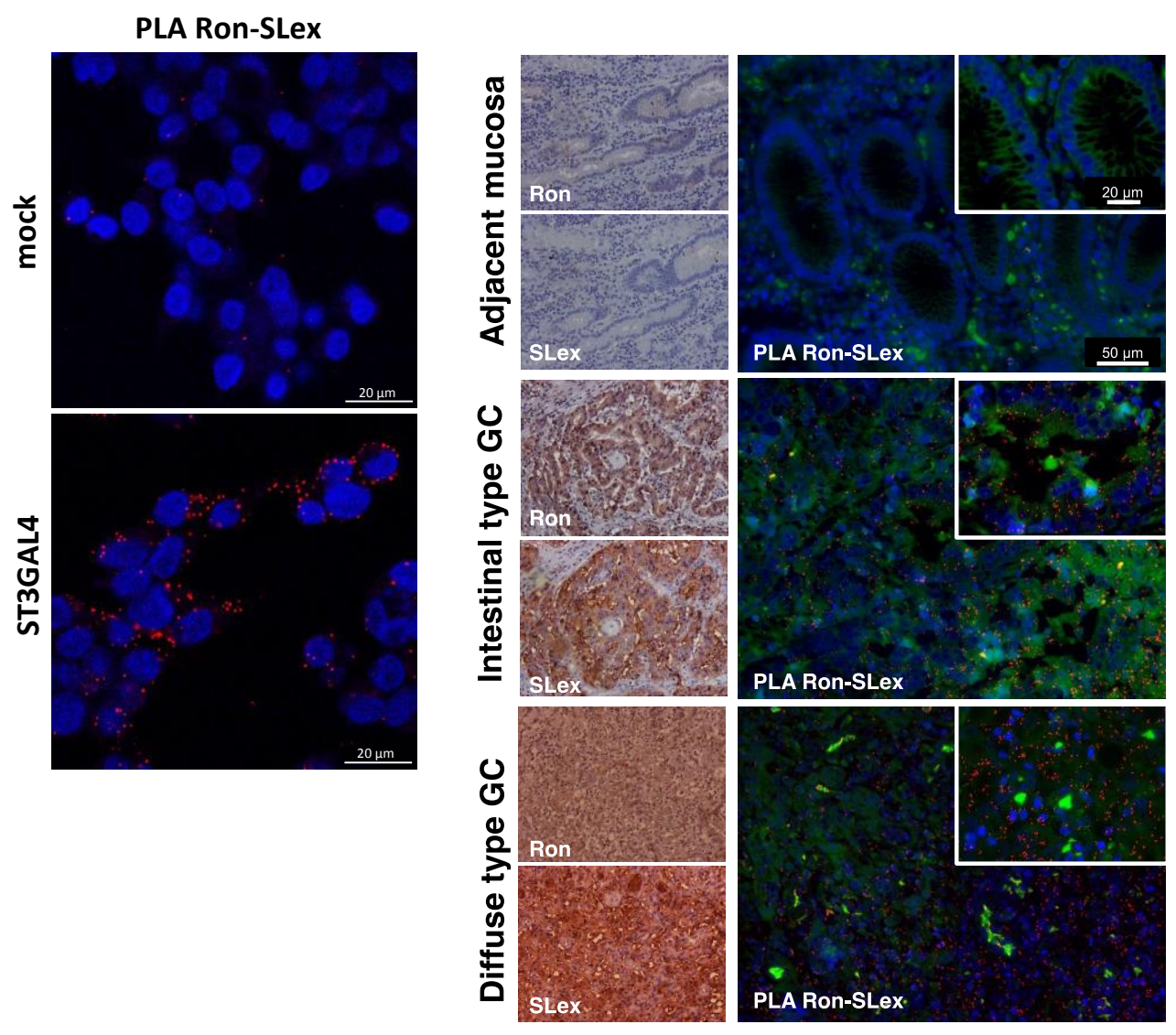

Figure 8. Receptor tyrosine kinase RON is aberrantly glycosylated with $S L e^{x}$ in gastric cancer

A. The mock transfected cell line is largely negative in the PLA for RON and SLe ${ }^{x}$. On the other hand $\mathrm{ST}_{3} \mathrm{GAL}_{4}$ overexpressing cells show strong PLA signal, confirming altered glycosylation of the RON receptor in these cells. The PLA signal is shown in red and nuclei in blue.

B. Screening of gastric tumor samples with IHC for RON or SLe ${ }^{x}$ (left panel) and PLA for RON and $\mathrm{SLe}^{\mathrm{x}}$ (right panel). Adjacent mucosa is negative for $\mathrm{SLe}^{\mathrm{x}}$ and expresses low level of RON as shown by IHC. The PLA experiment shows no signal in the adjacent mucosa and resembles an internal negative control. The selected cases of intestinal type GC and diffuse type GC are positive for SLe ${ }^{x}$ and RON. Evaluation of colocalization by PLA reveals that RON is a carrier of SLe $e^{x}$ in gastric carcinomas. The PLA signal is shown in red and nuclei in blue. Tissue autofluoresence has been used to visualize the tissue structure (green). 
Table 1. Antibodies and lectins

\begin{tabular}{|c|c|c|c|c|c|}
\hline $\begin{array}{l}\text { Antibody/ } \\
\text { Lectin }\end{array}$ & Manufacturer & Type & $\begin{array}{l}\text { Dil. for } \\
\text { WB }\end{array}$ & $\begin{array}{l}\text { Dil. for } \\
\mathrm{IHC/IF}\end{array}$ & Ref. \\
\hline KM93; Anti-SLe ${ }^{X}$ & Millipore, Billerica, MA & Mouse IgM & $1: 500$ & $1: 60$ & {$[22]$} \\
\hline C-20, Anti-RON & Santa Cruz Biotechnology, Dallas, TX & Rabbit IgG & $1: 1000$ & $1: 60$ & \\
\hline Anti-p-RON & Santa Cruz Biotechnology & Rabbit IgG & $1: 1000$ & $1: 60$ & \\
\hline SNA, Biotinylated & Vector Laboratories, Burlingame, CA & Lectin & $1: 600$ & & {$[\underline{80}]$} \\
\hline
\end{tabular}

Rua Alfredo Allen, 208 4200-135 Porto 